\section{[60]Fullerene Complexes with Supramolecular Zinc Tetraphenylporphyrin Assemblies: Synthesis, Crystal Structures, and Optical Properties}

\author{
Aleksey L. Litvinov, ${ }^{*} \dagger$ Dmitri V. Konarev, ${ }^{\dagger}$ Andrey Yu. Kovalevsky, ${ }^{\ddagger}$ \\ Ivan S. Neretin, ${ }^{\S}$ Philip Coppens, ${ }^{\ddagger}$ and Rimma N. Lyubovskaya ${ }^{*, \dagger}$ \\ Institute of Problems of Chemical Physics RAS, Chernogolovka, \\ Moscow Region 142432, Russia, Department of Chemistry, State University of New York at \\ Buffalo, Buffalo, New York, 14214, and Institute of Organoelement Compounds RAS, \\ 28 Vavilov Street, 119991, Moscow, Russia
}

Received March 15, 2005; Revised Manuscript Received June 24, 2005

\begin{abstract}
Different mono-, bi-, and tetradentate N- and O-containing ligands (L) were used in the design of monomer, dimer, and pentamer zinc tetraphenylporphyrin (ZnTPP) assemblies, which then cocrystallized with fullerene $\mathrm{C}_{60}$. Those were pyrazine (1); 4,4'-bipyridyl (2, 8, 9 (with CoTPP)); tetra(4-pyridyl)porphyrin (3); tetrahydrofuran (4); $N, N, N^{\prime}, N^{\prime}$-tetramethyldiaminomethane (5); $N, N, N^{\prime}, N^{\prime}$-tetramethyldiaminoethane (6); $N, N, N^{\prime}, N^{\prime}$ tetramethyldiaminobutene (7); and 1,4-bi-(4,4'-pyridyl)ethylene (10). Molecular structures of new ZnTPP oligomers were described. ZnTPP units, concaved as a result of ligand coordination, effectively cocrystallized with nearly spherical fullerene molecules to produce a variety of packing motifs of fullerenes, namely, three-dimensional (3D) packing in $\mathbf{4}$, one-dimensional (1D) zigzag chains in $\mathbf{6}$, a pair arrangement in $\mathbf{1}$ and $\mathbf{3}$, and isolated packing in $\mathbf{2}$. The $\mathrm{Zn} \cdots \mathrm{N}(\mathrm{L})$ bonds were either arranged nearly parallel to the planes of the ligand or bent up to $33^{\circ}$ relative to this plane. The characteristic $\mathrm{Zn} \cdots \mathrm{N}(\mathrm{L})$ bond lengths were $2.13-2.21 \AA$, whereas the $\mathrm{Zn} \cdots \mathrm{C}\left(\mathrm{C}_{60}\right)$ distances were essentially longer $\left(3.10-3.29 \AA\right.$ ). Coordination with ligands and $\mathrm{C}_{60}$ noticeably shifted the Soret band of ZnTPP to the red side (up to $12 \mathrm{~nm}$ ) and two Q-bands (up to $26 \mathrm{~nm}$ ). According to visible-NIR and IR spectra, the complexes had a neutral ground state with charge-transfer bands at 760-820 nm depending on a ZnTPP·L assembly.
\end{abstract}

\section{Introduction}

Fullerenes and fullerene-based materials show a number of distinctive electronic and photophysical properties, which make them promising candidates to be used in plastic solar cells and models of artificial photosynthesis. ${ }^{1}$ Special interest is focused on fullerene complexes with porphyrins and metalloporphyrins as natural chromophores strongly absorbing in the visible range. Up to now, a large number of covalently and noncovalently linked dyad and triad molecules based on fullerenes and porphyrins have been synthesized. ${ }^{2}$ Upon photoexcitation of a porphyrin part of a dyad or triad, the excited triplet state of porphyrin was efficiently quenched by fast charge transfer (CT) to an acceptor fullerene molecule to form relatively long-lived charge-separated states. ${ }^{2,3}$ Donor-acceptor complexes of fullerenes with porphyrins were also intensely studied along with dyads and triads. Fullerenes were shown to cocrystallize with metal octaethyl $-^{4}$ and tetraphenylporphyrins $^{5}$ as well as more complicated porphyrin molecules. ${ }^{6}$ The ground state of these donor-acceptor complexes ranged from a neutral to an ionic one ${ }^{4-7} \mathrm{~A}$ relatively strong interaction between a central metal atom of porphyrin and a fullerene cage allowed one to study molecular structures of fullerene derivatives and endometallofullerenes. ${ }^{4 a, 8}$ Several approaches were used to develop fullerene/porphyrin architectures in the solid state. A multicomponent approach afforded ionic complexes of a general formula: $\left[\left(\mathrm{D}_{1}^{+}\right) \cdot\left(\mathrm{CoTPP} \cdot \mathrm{C}_{60}{ }^{-}\right) \cdot\right.$ solvent $]$

* Corresponding authors. (R.N.L.) FAX: +007-096-522-18-52. Email: lyurn@icp.ac.ru; (A.L.L.) E-mail: litvin@cat.icp.ac.ru.

$\dagger$ Institute of Problems of Chemical Physics RAS.

$¥$ State University of New York at Buffalo.

$\S$ Institute of Organoelement Compounds RAS.
( $\mathrm{D}_{1}$ : bis(benzene)chromium; tetrakis(dimethylamino)ethylene; tetramethylammonium; $N$-methylpyridinium; CoTPP: cobalt(II) tetraphenylporphyrin). ${ }^{9}$ Metal-bridged pyridyl-substituted porphyrins formed another family of fullerene/porphyrin complexes. ${ }^{10}$ Another interesting approach is a supramolecular one suggesting that different N-containing ligands, which form porphyrin assemblies in solution can effectively cocrystallize with fullerenes. A large amount of accumulated experience has allowed the preparation of such assemblies in solution and in the solid state without fullerenes..$^{11}$ For example, pyridine (Py), pyrazine (Prz), 4,4'-bipyridyl (BPy), 1,4-bi-(4,4'-pyridyl)ethylene (BPE), tetra(4-pyridyl)porphyrin (4-TPyP), and other N-containing molecules form coordination assemblies with metalloporphyrins. Such assemblies can be monomers, dimers, trimers, pentamers, and even polymers. ${ }^{11}$ The N-containing ligand length affects an interplanar distance between metalloporphyrins, oligomer conformation, and the size of channels or cavities in a supramolecular structure ${ }^{11 \mathrm{a}-\mathrm{c}}$ defining a large synthetic potential of such assemblies for the design of new donor-acceptor complexes with fullerenes. The study of photoinduced CT between $\mathrm{C}_{60}$ and coordination porphyrin pentamers: $(\mathrm{RuTPP} \cdot \mathrm{CO})_{4} \cdot(3-\mathrm{TPyP})$, and $(\mathrm{RuTPP} \cdot \mathrm{CO})_{4} \cdot(4-\mathrm{TPyP})$ (RuTPP.CO: ruthenium(II) carbonyl tetraphenylporphyrinate; 3-TPyP: tetra(3-pyridyl)porphyrin) in solution showed such assemblies to be promising building blocks to be used in the development of photoactive fullerene/porphyrin complexes. ${ }^{12}$ Previously, we characterized several complexes of $\mathrm{C}_{60}$ and $\mathrm{C}_{70}$ with monomeric ZnTPP.Py and CoTPP.Py units. ${ }^{10 \mathrm{~d}}$ The preliminary data on two supramolecular $\mathrm{C}_{60}$ complexes with 


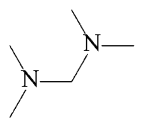

TMDAM

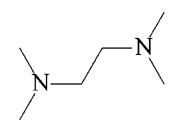

TMDAE

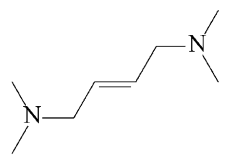

TMDAB

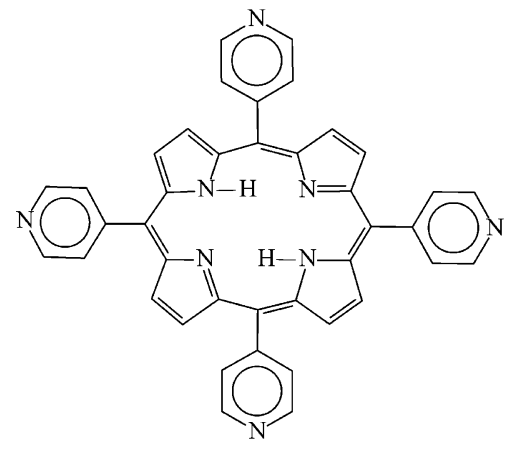

$\mathrm{H}_{2}$ TPyP

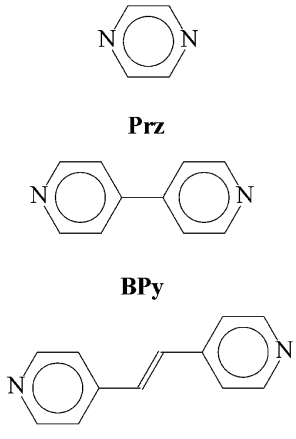

BPE
Figure 1. Molecular structures of the ligands used for the preparation of supramolecular assemblies with ZnTPP.

$(\mathrm{ZnTPP})_{2} \cdot \operatorname{Prz}$ dimers and $(\mathrm{ZnTPP})_{4} \cdot(4-\mathrm{TPyP})$ pentamers were also presented in communications. ${ }^{13}$

In this paper, we report a series of new fullerene $\mathrm{C}_{60}$ complexes with supramolecular zinc tetraphenylporphyrin assemblies bound by different $\mathrm{N}$ - and O-containing ligands, which range from monomeric to pentameric. Pyrazine (Prz, 1); 4,4'-bipyridyl (BPy, 2); tetra(4-pyridyl)porphyrin (4-TPyP, 3); tetrahydrofuran (THF, 4); $N, N, N^{\prime}, N^{\prime}$-tetramethyldiaminomethane (TMDAM, 5); $N, N, N^{\prime}, N^{\prime}$-tetramethyldiaminoethane (TMDAE, 6); $N, N, N^{\prime}, N^{\prime}$-tetramethyldiaminobutene (TMDAB, 7) were used as ligands (Figure 1). Synthesis, crystal structures of 1-4 and 6, and optical properties of 1-7 are described. Crystal structures of three metalloporphyrin dimers of ZnTPP and CoTPP with BPy (8 and 9) and ZnTPP with 1,4-bi-(4,4'-pyridyl)ethylene (10) without fullerenes are also presented, and the geometry of $\mathbf{8}$ is compared with that of a porphyrin dimer in a complex with $\mathrm{C}_{60}(\mathbf{2})$.

\section{Experimental Section}

General. UV-visible-NIR spectra were measured on a Shimadzu-3100 spectrometer in the $240-2600 \mathrm{~nm}$ range. FTIR spectra were measured in $\mathrm{KBr}$ pellets with a Perkin-Elmer 1000 Series spectrometer $\left(400-4000 \mathrm{~cm}^{-1}\right)$.

Materials. All chemicals were purchased from Aldrich and used without further purification. Solvents were dried by distillation under argon over $\mathrm{Na}$ /benzophenone for benzene $\left(\mathrm{C}_{6} \mathrm{H}_{6}\right)$, toluene $\left(\mathrm{C}_{6} \mathrm{H}_{5} \mathrm{CH}_{3}\right)$, and tetrahydrofuran (THF), over $\mathrm{P}_{2} \mathrm{O}_{5}$ for chlorobenzene $\left(\mathrm{C}_{6} \mathrm{H}_{5} \mathrm{Cl}\right)$, and over $\mathrm{Na}$ under reduced pressure for benzonitrile $\left(\mathrm{C}_{6} \mathrm{H}_{5} \mathrm{CN}\right)$ and were stored under argon.

Synthesis. The crystals of $\mathbf{1}-\mathbf{7}$ were prepared by the slow evaporation of a solvent containing fullerene, corresponding porphyrin, and $\mathrm{N}$ - or $\mathrm{O}$-containing ligand under argon during 5-10 days. The crystals of $\mathbf{8}$ were obtained as an admixture in the synthesis of $\mathbf{2}$. The crystals of $\mathbf{9}$ and $\mathbf{1 0}$ were obtained in the syntheses with fullerenes; however, they did not contain $\mathrm{C}_{60}$ according to IR spectra and X-ray diffraction on a single crystal. The crystals of all complexes were primarily identified by IR spectroscopy, and their composition was studied by X-ray diffraction on a single crystal $(\mathbf{1}-\mathbf{5}, \mathbf{6}, \mathbf{8}-\mathbf{1 0})$ and elemental analysis (5 and 7). The unit cell parameters of several crystals from each synthesis were tested to justify the identity of the crystals in one synthesis. The resulting complexes and their characteristics are listed in Table 1.

The crystals of $\left[(\mathrm{ZnTPP})_{2} \cdot \operatorname{Prz}\right] \cdot \mathrm{C}_{60} \cdot\left(\mathrm{C}_{6} \mathrm{H}_{5} \mathrm{CH}_{3}\right)_{5.34} \cdot$ $\left(\mathrm{C}_{6} \mathrm{H}_{5} \mathrm{CN}\right)_{0.66}(\mathbf{1})$ and $\left[(\mathrm{ZnTPP})_{2} \cdot \mathrm{BPy}\right] \cdot\left(\mathrm{C}_{60}\right)_{2} \cdot\left(\mathrm{C}_{6} \mathrm{H}_{5} \mathrm{CH}_{3}\right)_{4}(\mathbf{2})$ were prepared by the evaporation of a toluene/benzonitrile $(10: 1 \mathrm{v} / \mathrm{v})$ solution $(22 \mathrm{~mL})$ containing zinc tetraphenylporphyrin (ZnT$\mathrm{PP}, 37 \mathrm{mg}, 0.056 \mathrm{mmol})$, pyrazine (Prz, 1) $(22 \mathrm{mg}, 0.27 \mathrm{mmol})$, or 4,4'-bipyridyl (BPy, 2) $(43 \mathrm{mg}, 0.27 \mathrm{mmol})$ and $\mathrm{C}_{60}(20 \mathrm{mg}$, $0.027 \mathrm{mmol}$ ) at a $2: 10: 1 \mathrm{molar}$ ratio. The solvent was decanted from the crystals precipitated, which were then washed with dry hexane to yield black prisms of $\mathbf{1}$ (90\% yield) and black plates of 2 (60\% yield). The fullerene free crystals of [( $\mathrm{ZnTPP})_{2}$. $\mathrm{BPy}] \cdot\left(\mathrm{C}_{6} \mathrm{H}_{5} \mathrm{CN}\right)_{4}(\mathbf{8})$ were obtained as black prisms in the synthesis of $\mathbf{2}$ as an admixture with $30 \%$ yield. They were separated from the crystals of $\mathbf{2}$ under a microscope according to the crystal shape. The crystals of $\mathbf{1}$ and $\mathbf{2}$ were unstable in storage and slowly decomposed because of the loss of solvent.

The crystals of $\left[(\mathrm{ZnTPP})_{4} \cdot(4-\mathrm{TPyP})\right] \cdot\left(\mathrm{C}_{60}\right)_{2} \cdot\left(\mathrm{C}_{6} \mathrm{H}_{5} \mathrm{CN}\right)_{3.5}(3)$ were prepared by the evaporation of a chlorobenzene/benzonitrile solution $(15: 1 \mathrm{v} / \mathrm{v})(16 \mathrm{~mL})$ containing ZnTPP $(37 \mathrm{mg}$, $0.056 \mathrm{mmol}$ ), tetra(4-pyridyl)porphyrin (4-TPyP, $9 \mathrm{mg}, 0.014$ $\mathrm{mg})$, and $\mathrm{C}_{60}(20 \mathrm{mg}, 0.028 \mathrm{mmol})$ at a 4:1:2 molar ratio. The solvent was decanted from the crystals, which were then washed with dry hexane to yield black plates with blue luster (70\% yield).

The crystals of $(\mathrm{ZnTPP} \cdot \mathrm{THF})_{2} \cdot\left(\mathrm{C}_{60}\right)_{6.4} \cdot \mathrm{C}_{6} \mathrm{H}_{5} \mathrm{Cl}$ (4) were prepared by the evaporation of a chlorobenzene solution containing ZnTPP (19 mg, $0.027 \mathrm{mmol})$ and $\mathrm{C}_{60}(20 \mathrm{mg}, 0.027 \mathrm{mmol})$ at a 1:1 molar ratio in the presence of tetrahydrofuran (THF) vapor. The crystals were washed with acetone to yield large black plates of 4 (70\% yield).

The crystals of $\left[(\mathrm{ZnTPP})_{2} \cdot \mathrm{TMDAM}\right] \cdot \mathrm{C}_{60} \cdot \mathrm{C}_{6} \mathrm{H}_{5} \mathrm{Cl}(\mathbf{5})$, [ZnTPP. TMDAE] $\cdot \mathrm{C}_{60} \cdot\left(\mathrm{C}_{6} \mathrm{H}_{6}\right)_{0.7} \cdot\left(\mathrm{C}_{6} \mathrm{H}_{5} \mathrm{Cl}\right)_{0.3}(\mathbf{6})$, and $\left[(\mathrm{ZnTPP})_{2} \cdot(\mathrm{TMDAB})\right] \cdot$ $\left(\mathrm{C}_{60}\right)_{2} \cdot\left(\mathrm{C}_{6} \mathrm{H}_{5} \mathrm{Cl}\right)_{4} \cdot \mathrm{C}_{6} \mathrm{H}_{5} \mathrm{CN}(\mathbf{7})$ were prepared by the evaporation of a chlorobenzene/benzene solution $(10: 1 \mathrm{v} / \mathrm{v})(16 \mathrm{~mL})$ containing ZnTPP (19 mg, $0.027 \mathrm{mmol})$ and $\mathrm{C}_{60}(20 \mathrm{mg}, 0.027 \mathrm{mmol})$ at a 1:1 molar ratio and a large excess of $N, N, N^{\prime}, N^{\prime}$-tetramethyldiaminomethane (TDMAM, 5), $N, N, N^{\prime}, N^{\prime}$-tetramethyldiaminoethane (TMDAE, 6), and $N, N, N^{\prime}, N^{\prime}$-tetramethyldiaminobutene (TMDAB, 7) $(0.5 \mathrm{~mL})$. The solvent was decanted from the crystals, which were then washed with acetone to yield dark red plates of $\mathbf{5}$ and dark red parallelepipeds of $\mathbf{6}$ and $\mathbf{7}$ with characteristic blue luster (50-80\% yield). The use of $N, N, N^{\prime}, N^{\prime}$-tetramethyldiaminohexane (TMDAH) in similar conditions afforded only fullerene-free crystals of the (ZnTPP). TMDAH complex according to the IR spectrum.

The crystals of $\left[(\mathrm{CoTPP})_{2} \cdot \mathrm{BPy}\right] \cdot\left(\mathrm{C}_{6} \mathrm{H}_{5} \mathrm{CN}\right)_{4}(\mathbf{9})$ and $\left[(\mathrm{ZnTPP})_{2}\right.$. $\mathrm{BPE}] \cdot \mathrm{BPE} \cdot\left(\mathrm{C}_{6} \mathrm{H}_{5} \mathrm{CN}\right)_{3} \cdot \mathrm{C}_{6} \mathrm{H}_{5} \mathrm{Me}(\mathbf{1 0})$ were obtained by the evaporation of a toluene/benzonitrile $(10: 1 \mathrm{v} / \mathrm{v})$ solution $(22 \mathrm{~mL})$ containing cobalt(II) tetraphenylporphyrin (CoTPP, $36 \mathrm{mg}$, $0.054 \mathrm{mmol}), \mathrm{BPy}(44 \mathrm{mg}, 0.27 \mathrm{mmol})$, and $\mathrm{C}_{60}(20 \mathrm{mg}, 0.027$ $\mathrm{mmol}$ ) at a 2:10:1 molar ratio (9) or ZnTPP (36 mg, 0.054 $\mathrm{mmol}$ ), 1,2-bi-(pyridyl)ethylene (BPE, $46 \mathrm{mg}, 0.27 \mathrm{mmol}$ ), and $\mathrm{C}_{60}(20 \mathrm{mg}, 0.027 \mathrm{mmol})$ at a $2: 10: 1$ molar ratio $(\mathbf{1 0})$. Dark red parallelepipeds of 9 and $\mathbf{1 0}$ crystallized without $\mathrm{C}_{60}$ according to the IR spectra and X-ray diffraction data on a single crystal. The crystals were washed with hexane $(30-40 \%$ yield).

X-ray Diffraction Studies. Crystallographic data 1-4, 6, 8-10 are summarized in Table 2. X-ray diffraction data on $\mathbf{1}$, 2, 4, 6, 8-10 were collected at 90(1) K using a Bruker SMART1000 CCD diffractometer installed at a rotating anode source (Mo K $\alpha$ radiation, $\lambda=0.71073 \AA$ ), and equipped with an Oxford Cryosystems nitrogen gas-flow apparatus. The data were collected by the rotation method with $0.3^{\circ}$ frame-width ( $\omega$ scan) and 10-40 s exposure time per frame. Four sets of data (500-600 frames in each set) were collected, nominally covering half of the reciprocal space. The data were integrated, scaled, sorted, and averaged using the SMART software package. ${ }^{14}$ The structure was solved by the Patterson method using SHELXTL NT Version 5.10. ${ }^{15}$ The structure was refined by full-matrix least squares against $\mathrm{F}^{2}$. Non-hydrogen atoms were refined in anisotropic approximation. Hydrogen atoms were revealed from difference Fourier maps and refined in idealized positions for $\mathrm{CH}_{3} \mathrm{H}$-atoms or using a "riding" model for the remaining hydrogens $\left(U_{\text {iso }}=1.5 U_{\text {eq }}\right.$ of the preceding 
Table 1. Data for Crystals of 1-10

\begin{tabular}{|c|c|c|c|c|c|}
\hline \multirow[b]{2}{*}{$\mathrm{N}$} & \multirow[b]{2}{*}{ complex } & \multicolumn{4}{|c|}{ elemental analysis, found/calc } \\
\hline & & $\mathrm{C}, \%$ & $\mathrm{H}, \%$ & $\mathrm{~N}, \%$ & $\mathrm{Cl}, \%$ \\
\hline $\mathbf{1}$ & {$\left[(\mathrm{ZnTPP})_{2} \cdot \mathrm{Prz}\right] \cdot \mathrm{C}_{60} \cdot\left(\mathrm{C}_{6} \mathrm{H}_{5} \mathrm{CH}_{3}\right)_{5.34} \cdot\left(\mathrm{C}_{6} \mathrm{H}_{5} \mathrm{CN}\right)_{0.66}$} & \multicolumn{4}{|c|}{ according to data of X-ray diffraction measurements } \\
\hline 2 & {$\left[(\mathrm{ZnTPP})_{2} \cdot \mathrm{BPy}\right] \cdot\left(\mathrm{C}_{60}\right)_{2} \cdot\left(\mathrm{C}_{6} \mathrm{H}_{5} \mathrm{CH}_{3}\right)_{4}$} & \multicolumn{4}{|c|}{ according to data of X-ray diffraction measurements } \\
\hline 3 & {$\left[(\mathrm{ZnTPP})_{4} \cdot(4-\mathrm{TPyP})\right] \cdot\left(\mathrm{C}_{60}\right)_{2} \cdot\left(\mathrm{C}_{6} \mathrm{H}_{5} \mathrm{CN}\right)_{3.5}$} & \multicolumn{4}{|c|}{ according to data of X-ray diffraction measurements } \\
\hline 4 & {$[\mathrm{ZnTPP} \cdot \mathrm{THF}]_{2} \cdot\left(\mathrm{C}_{60}\right)_{6.4} \cdot\left(\mathrm{C}_{6} \mathrm{H}_{5} \mathrm{Cl}\right)$} & \multicolumn{4}{|c|}{ according to data of X-ray diffraction measurements } \\
\hline \multirow[t]{2}{*}{5} & {$\left[(\mathrm{ZnTPP})_{2} \cdot \mathrm{TMDAM}\right] \cdot \mathrm{C}_{60} \cdot \mathrm{C}_{6} \mathrm{H}_{5} \mathrm{Cl}$} & 82.61 & 4.33 & 6.36 & $a$ \\
\hline & & 82.58 & 4.33 & 6.27 & 1.55 \\
\hline 6 & {$[\mathrm{ZnTPP} \cdot \mathrm{TMDAE}] \cdot \mathrm{C}_{60} \cdot\left(\mathrm{C}_{6} \mathrm{H}_{6}\right)_{0.7} \cdot\left(\mathrm{C}_{6} \mathrm{H}_{5} \mathrm{Cl}\right)_{0.3}$} & \multicolumn{4}{|c|}{ according to data of X-ray diffraction measurements } \\
\hline \multirow[t]{2}{*}{7} & {$\left[(\mathrm{ZnTPP})_{2} \cdot(\mathrm{TMDAB})\right] \cdot\left(\mathrm{C}_{60}\right)_{2} \cdot\left(\mathrm{C}_{6} \mathrm{H}_{5} \mathrm{Cl}\right)_{4} \cdot \mathrm{C}_{6} \mathrm{H}_{5} \mathrm{CN}$} & 88.74 & 2.81 & 4.34 & 4.11 \\
\hline & & 88.67 & 2.86 & 4.41 & 4.06 \\
\hline 8 & {$\left[(\mathrm{ZnTPP})_{2} \cdot \mathrm{BPy}\right] \cdot\left(\mathrm{C}_{6} \mathrm{H}_{5} \mathrm{CN}\right)_{4}$} & \multicolumn{4}{|c|}{ according to data of X-ray diffraction measurements } \\
\hline 9 & {$\left[(\mathrm{CoTPP})_{2} \cdot \mathrm{BPy}\right] \cdot\left(\mathrm{C}_{6} \mathrm{H}_{5} \mathrm{CN}\right)_{4}$} & \multicolumn{4}{|c|}{ according to data of X-ray diffraction measurements } \\
\hline 10 & {$\left[(\mathrm{ZnTPP})_{2} \cdot \mathrm{BPE}\right] \cdot \mathrm{BPE} \cdot\left(\mathrm{C}_{6} \mathrm{H}_{5} \mathrm{CN}\right)_{3} \cdot \mathrm{C}_{6} \mathrm{H}_{5} \mathrm{Me}$} & \multicolumn{4}{|c|}{ according to data of X-ray diffraction measurements } \\
\hline
\end{tabular}

${ }^{a}$ It was impossible to determine the content of $\mathrm{Cl}$ in the presence of zinc. However, the IR spectrum of 5 showed the absorption bands at $467,684,740,1473$, and $1576 \mathrm{~cm}^{-1}$, attributable to $\mathrm{C}_{6} \mathrm{H}_{5} \mathrm{Cl}$.

carbon atom for $\mathrm{CH}_{3}$ hydrogens and $U_{\text {iso }}=1.2 U_{\text {eq }}$ for the remaining $\mathrm{H}$-atoms).

$\left[(\mathrm{ZnTPP})_{2} \cdot \mathrm{Prz}\right] \cdot \mathbf{C}_{60} \cdot\left(\mathrm{C}_{6} \mathrm{H}_{5} \mathrm{CH}_{3}\right)_{5.34} \cdot\left(\mathrm{C}_{6} \mathrm{H}_{5} \mathrm{CN}\right)_{0.66}$ (1). The asymmetric unit contains ordered $(\mathrm{ZnTPP})_{2} \cdot \operatorname{Prz}$ and $\mathrm{C}_{60}$ units as well as toluene and benzonitrile molecules, which occupy six different positions. Toluene molecules are ordered in two positions and disordered in two other positions about a noncrystallographic inversion center residing in the center of the toluene benzene ring. Two remaining positions are shared by both toluene and benzonitrile molecules (toluene/benzonitrile ratio is $0.54 / 0.44$ and $0.78 / 0.22$ ). This results in noninteger stoichiometry of the complex.

Several restraints were used to bring the length of some fullerene bonds and disordered solvent molecules to reasonable values. 5-6 and 6-6 bonds of the fullerene molecule were restrained to their ideal values $1.450(3)$ and $1.380(3) \AA$, respectively. Benzene rings of toluene and benzonitrile molecules were restrained to be perfect hexagons with $\mathrm{C}-\mathrm{C}$ bonds of $1.390 \AA$. All $\mathrm{CH}_{3}-\mathrm{C}_{\mathrm{Ar}}$ bonds of the solvent molecules were restrained to $1.450(3) \AA$, while all $\mathrm{N} \equiv \mathrm{C}_{\mathrm{Ar}}$ bonds of the disordered benzonitrile molecules were restrained to $1.210(3)$ $\AA$. Carbon atoms of strongly disordered toluene molecules were refined in isotropic approximation and bond lengths were restrained to $1.390(2) \AA\left(\mathrm{C}_{\mathrm{Ar}}-\mathrm{C}_{\mathrm{Ar}}\right)$ and $1.450(3) \AA\left(\mathrm{C}_{\mathrm{Me}}-\mathrm{C}_{\mathrm{Ar}}\right)$.

$\left[(\mathbf{Z n T P P})_{2} \cdot \mathbf{B P y}\right] \cdot\left(\mathrm{C}_{60}\right)_{2} \cdot\left(\mathbf{C}_{6} \mathbf{H}_{5} \mathbf{C H}_{3}\right)_{4}(\mathbf{2})$. The asymmetric unit contains the $(\mathrm{ZnTPP})_{2} \cdot \mathrm{Bpy}$ dimer, two $\mathrm{C}_{60}$, and four toluene molecules. All molecules reside in general positions.

Huge volume of the unit cell and small size of the crystal $(0.3 \times 0.05 \times 0.01 \mathrm{~mm})$ resulted in a large $R_{\text {int }}$ value $(0.239)$ and prevented the final $R_{1}$ factor to be refined to lower than 0.111 . All five-membered rings in one fullerene molecule were constrained to be ideal pentagons with $\mathrm{C}-\mathrm{C}$ bonds of $1.420(2)$ $\AA$, whereas the remaining $5-6$ and $6-6$ bonds were restrained to be equal to 1.450 (3) and 1.395(3) $\AA$. Additionally, some of 5-6 and 6-6 bonds of another fullerene molecule were also restrained in a similar way.

$\left[(\mathbf{Z n T P P})_{4} \cdot(4-\mathbf{T P y P})\right] \cdot\left(\mathbf{C}_{60}\right)_{2} \cdot\left(\mathbf{C}_{6} \mathbf{H}_{5} \mathbf{C N}\right)_{3.5}$ (3). The asymmetric unit of $\mathbf{3}$ contains $\mathrm{ZnTPP}, \mathrm{C}_{60}$, general positions partially occupied by $\mathrm{C}_{6} \mathrm{H}_{5} \mathrm{CN}$ molecules, and the 4-TPyP molecule at an inversion center. The $\mathrm{C}_{60}$ molecules are disordered between two orientations with 35:65 occupancy, and one of the ZnTPP molecules (molecule $\mathbf{B}$ ) is disordered between two orientations with 40:60 occupancy. Other details for the crystal structure determination for $\mathbf{3}$ are given elsewhere. ${ }^{13 \mathrm{~b}}$

$(\mathbf{Z n T P P} \cdot \mathbf{T H F})_{2} \cdot\left(\mathbf{C}_{60}\right)_{6.4} \cdot \mathbf{C}_{6} \mathbf{H}_{5} \mathbf{C l}$ (4). The asymmetric unit of 4 involves seven crystallographically independent fullerene molecules, two ZnTPP.THF units, and two positions of $\mathrm{C}_{6} \mathrm{H}_{5} \mathrm{Cl}$ molecules. Thus, the number of non-hydrogen atoms in the asymmetric unit is 544, whereas the crystal diffracts only up to $2 \theta=46^{\circ}$. Non-hydrogen atoms of two ZnTPP.THF and five fullerene molecules in the asymmetric unit were refined anisotropically. All bonds in the sixth $\mathrm{C}_{60}$ molecule were constrained to their ideal values [1.450(3) for $5-6$ and 1.395(2) $\AA$ for 6-6 bonds], and its atoms were refined isotropically. The seventh $\mathrm{C}_{60}$ molecule is partially occupied, with the population refined to $40 \%$. Because of partial occupancy, the fullerene molecule could not been found from the electron density Fourier synthesis and, therefore, was fitted to its position and refined as a rigid body. Two positions of the chlorobenzene molecule were only $50 \%$ populated. The benzene rings in $\mathrm{C}_{6} \mathrm{H}_{5} \mathrm{Cl}$ were constrained to be ideal hexagons with the $\mathrm{C}-\mathrm{C}$ bonds of $1.390(2) \AA$.

The presence of an enormous number of non-hydrogen atoms, partial occupation of a crystallographic site by one fullerene molecule, and partially populated solvent molecules resulted in poorly refined parameters $\left(R_{1}=0.216 \%\right)$.

[ZnTPP·TMDAE] $\cdot \mathbf{C}_{60} \cdot\left(\mathbf{C}_{6} \mathrm{H}_{6}\right)_{0.7} \cdot\left(\mathbf{C}_{6} \mathbf{H}_{5} \mathbf{C l}\right)_{0.3}(6)$. The asymmetric unit contains the ZnTPP.TMDAE unit, the ordered $\mathrm{C}_{60}$ molecule, and one position of a solvent one. This position is occupied by benzene and chlorobenzene molecules with $0.7 /$ 0.3 populations, respectively. Their atoms were refined isotropically, while benzene rings were constrained geometrically to be ideal hexagons with $1.390(2) \AA \mathrm{C}_{\mathrm{Ar}}-\mathrm{C}_{\mathrm{Ar}}$ bonds. The crystal is a racemic twin, with the second enantiomer population refined to be $0.259(9) \%$.

$\left[(\mathrm{ZnTPP})_{2} \cdot \mathrm{BPy}\right] \cdot\left(\mathrm{C}_{6} \mathrm{H}_{5} \mathrm{CN}\right)_{4}(8)$ and $\left[(\mathrm{CoTPP})_{2} \cdot \mathrm{BPy}\right] \cdot$ $\left(\mathbf{C}_{6} \mathbf{H}_{5} \mathbf{C N}\right)_{4}(\mathbf{9})$. The asymmetric unit contains half of the $(\mathrm{MTPP})_{2} \cdot \mathrm{BPy}$ dimer $(\mathrm{M}=\mathrm{Zn}$ and $\mathrm{Co})$, which resides at the inversion center located at the center of the central $\mathrm{C}-\mathrm{C}$ bond of $\mathrm{BPy}$ and two benzonitrile molecules.

$\left[(\mathrm{ZnTPP})_{2} \cdot \mathrm{BPE}\right] \cdot \mathrm{BPE} \cdot\left(\mathrm{C}_{6} \mathrm{H}_{5} \mathrm{CN}\right)_{3} \cdot \mathbf{C}_{6} \mathrm{H}_{5} \mathrm{Me}(10)$. Non-hydrogen atoms were refined in anisotropic approximation. Because of two benzonitrile molecules disordered, the anisotropic displacement parameters for some of their carbon atoms were restrained, while the bond length was constrained to its ideal value of $1.480(3) \AA$.

\section{Results and Discussion}

1. Crystal Structures of the Complexes. Geometry of the TPP macrocycles, selected bond distances, and bond angles in MTPP ( $\mathrm{M}=\mathrm{Zn}$ and $\mathrm{Co}$ ) and 4-TPyP molecules and the shortest metal-ligand $(\mathrm{M} \cdots \mathrm{N})$ and metal-fullerene $(\mathrm{M} \cdots \mathrm{C})$ contacts are listed in Table 3.

$\left[(\mathrm{ZnTPP})_{2} \cdot \mathrm{Prz}\right] \cdot \mathrm{C}_{60} \cdot\left(\mathrm{C}_{6} \mathrm{H}_{5} \mathrm{CH}_{3}\right)_{5.34} \cdot\left(\mathrm{C}_{6} \mathrm{H}_{5} \mathrm{CN}\right)_{0.66}(\mathbf{1})$. The $(\mathrm{ZnTPP})_{2} \cdot$ Prz dimers are arranged in a distorted hexagonal framework with large channels passing along the $a$-axis and accommodating double columns of fullerene molecules (Figure 2). Within the columns fullerenes form pairs separated by four toluene molecules. The center-to-center distance between fullerenes in a pair is $9.936 \AA$ with the shortest van der Waals C...C contact of $2.899 \AA$ (shown by dashed line in Figure $3)$. The sum of the van der Waals radii of two carbon atoms is $3.42 \AA .{ }^{16}$

$(\mathrm{ZnTPP})_{2} \cdot \operatorname{Prz}$ dimers alternate with $\mathrm{C}_{60}$ molecules along the $b$-axis, and each porphyrin dimer has two fullerene neighbors. $\mathrm{C}_{60}$ forms van der Waals contacts 
Table 2. Crystallographic Data

\begin{tabular}{|c|c|c|c|c|}
\hline & $\mathbf{1}^{13 \mathrm{a}}$ & 2 & $\mathbf{3}^{13 b}$ & 4 \\
\hline structural formula & $\begin{array}{l}{\left[(\mathrm{ZnTPP})_{2} \cdot \mathrm{Prz} \cdot \mathrm{C}_{60^{*}}\right.} \\
\quad\left(\mathrm{C}_{6} \mathrm{H}_{5} \mathrm{CH}_{3}\right)_{5.34^{\bullet}} \\
\quad\left(\mathrm{C}_{6} \mathrm{H}_{5} \mathrm{CN}\right)_{0.66}\end{array}$ & $\begin{array}{l}{\left[(\mathrm{ZnTPP})_{2} \cdot \mathrm{BPy}\right] \cdot} \\
\quad\left(\mathrm{C}_{60}\right)_{2} \cdot\left(\mathrm{C}_{6} \mathrm{H}_{5} \mathrm{CH}_{3}\right)_{4}\end{array}$ & $\begin{array}{l}{\left[(\mathrm{ZnTPP})_{4} \cdot(4-\mathrm{TPyP})\right] \cdot} \\
\left(\mathrm{C}_{60}\right)_{2} \cdot\left(\mathrm{C}_{6} \mathrm{H}_{5} \mathrm{CN}\right)_{3.5}\end{array}$ & $\begin{array}{l}{[\mathrm{ZnTPP} \cdot \mathrm{THF}]_{2} \cdot} \\
\quad\left(\mathrm{C}_{60}\right)_{6.4} \cdot\left(\mathrm{C}_{6} \mathrm{H}_{5} \mathrm{Cl}\right)\end{array}$ \\
\hline empirical formula & $\mathrm{C}_{190.5} \mathrm{H}_{98.02} \mathrm{~N}_{10.66} \mathrm{Zn}_{2}$ & $\mathrm{C}_{246} \mathrm{H}_{96} \mathrm{~N}_{10} \mathrm{Zn}_{2}$ & $\mathrm{C}_{180.5} \mathrm{H}_{77.75} \mathrm{~N}_{13.75} \mathrm{Zn}_{2}$ & $\mathrm{C}_{486} \mathrm{H}_{76} \mathrm{~N}_{8} \mathrm{O}_{2} \mathrm{ClZn}_{2}$ \\
\hline$F_{\mathrm{w}}, \mathrm{g} \mathrm{mol}^{-1}$ & 2666.80 & 3322.07 & 2566.55 & 6223.74 \\
\hline crystal shape & black prisms & black plates & black prisms & black plates \\
\hline crystal system & triclinic & monoclinic & triclinic & monoclinic \\
\hline space group & $P \overline{1}$ & $P 2_{1} / c$ & $\mathrm{P} \overline{1}$ & $P 2_{1} / c$ \\
\hline$a(\AA)$ & $13.3658(2)$ & $13.231(1)$ & $16.6488(10)$ & $32.438(1)$ \\
\hline$b(\AA)$ & $19.5386(3)$ & $49.036(5)$ & $19.0749(11)$ & $26.483(1)$ \\
\hline$c(\AA)$ & $24.7121(4)$ & $23.027(2)$ & $21.5917(13)$ & $35.080(2)$ \\
\hline$\alpha$, deg & $85.6754(3)$ & 90 & $90.344(2)$ & 90 \\
\hline$\beta, \operatorname{deg}$ & $84.5849(3)$ & $92.042(4)$ & $105.864(2)$ & $115.202(1)$ \\
\hline$\gamma$, deg & $88.3817(3)$ & 90 & $96.447(2)$ & 90 \\
\hline$V\left(\AA^{3}\right)$ & $6405.0(3)$ & $14930(3)$ & $6549.3(7)$ & $27267(2)$ \\
\hline$Z$ & 2 & 4 & 2 & 4 \\
\hline$D_{\mathrm{c}}\left(\mathrm{g} \mathrm{cm}^{-3}\right)$ & 1.383 & 1.478 & 1.301 & 1.516 \\
\hline$\mu\left(\mathrm{mm}^{-1}\right)$ & 0.443 & 0.397 & 0.431 & 0.268 \\
\hline$T(\mathrm{~K})$ & $90.0(1)$ & $90.0(1)$ & $110(2)$ & $90.0(1)$ \\
\hline $\max 2 \theta, \operatorname{deg}$ & 59.4 & 50.5 & 61.1 & 45.08 \\
\hline absorption correction & none & SADABS 2.05 & none & SADABS 2.05 \\
\hline reflections measured & 115208 & 154110 & 51690 & 135770 \\
\hline unique reflns $\left(\mathrm{R}_{\text {int }}\right)$ & $33340(0.043)$ & $26324(0.239)$ & $35781(0.0749)$ & $29288(0.049)$ \\
\hline reflns $F>4 \sigma(F)$ & 26069 & 10038 & 27934 & 18381 \\
\hline parameters refined & 1821 & 2217 & 1319 & 3945 \\
\hline $\mathrm{R}_{1}[F>4 \sigma(F)]$ & 0.062 & 0.111 & 0.0842 & 0.216 \\
\hline $\mathrm{wR}_{2}$ & 0.183 & 0.335 & 0.1959 & 0.563 \\
\hline GOF & 1.049 & 0.902 & 1.251 & 4.064 \\
\hline \multirow[t]{2}{*}{ extinction coefficient } & none & $0.00062(9)$ & none & none \\
\hline & 6 & 8 & 9 & 10 \\
\hline structural formula & $\begin{array}{c}\mathrm{ZnTPP} \cdot \mathrm{TMDAE}] \\
\mathrm{C}_{60} \cdot\left(\mathrm{C}_{6} \mathrm{H}_{6}\right)_{0.7} \\
\left(\mathrm{C}_{6} \mathrm{H}_{5} \mathrm{Cl}\right)_{0.3}\end{array}$ & $\begin{array}{l}{\left[(\mathrm{ZnTPP})_{2} \cdot \mathrm{BPy}\right] \cdot} \\
\left(\mathrm{C}_{6} \mathrm{H}_{5} \mathrm{CN}\right)_{4}\end{array}$ & $\begin{array}{c}{\left[(\mathrm{CoTPP})_{2} \cdot \mathrm{BPy}\right] \cdot} \\
\left(\mathrm{C}_{6} \mathrm{H}_{5} \mathrm{CN}\right)_{4}\end{array}$ & $\begin{array}{l}{\left[(\mathrm{ZnTPP})_{2} \cdot \mathrm{BPE}\right] \cdot} \\
\mathrm{BPE} \cdot\left(\mathrm{C}_{6} \mathrm{H}_{5} \mathrm{CN}\right)_{3} \cdot \\
\mathrm{C}_{6} \mathrm{H}_{5} \mathrm{CH}_{3}\end{array}$ \\
\hline empirical formula & $\mathrm{C}_{116} \mathrm{H}_{49.7} \mathrm{~N}_{6} \mathrm{Cl}_{0.3} \mathrm{Zn}$ & $\mathrm{C}_{126} \mathrm{H}_{84} \mathrm{~N}_{14} \mathrm{Zn}_{2}$ & $\mathrm{C}_{126} \mathrm{H}_{84} \mathrm{~N}_{14} \mathrm{Co}_{2}$ & $\mathrm{C}_{140} \mathrm{H}_{95} \mathrm{~N}_{15} \mathrm{Zn}_{2}$ \\
\hline$F_{\mathrm{w}}, \mathrm{g} \mathrm{mol}^{-1}$ & 1603.32 & 962.41 & 1911.93 & 2118.06 \\
\hline crystal shape & dark red parallelepipeds & black prisms & dark red parallelepipeds & dark red parallelepipeds \\
\hline crystal system & orthorhombic & monoclinic & monoclinic & triclinic \\
\hline space group & $P 2_{1} 2_{1} 2_{1}$ & $C 2 / c$ & $C 2 / c$ & $\mathrm{P} \overline{1}$ \\
\hline$a(\AA)$ & $15.0589(4)$ & $17.790(1)$ & $17.9296(7)$ & $11.3466(6)$ \\
\hline$b(\AA)$ & $19.1974(5)$ & $13.424(1)$ & $13.4047(5)$ & $11.3616(6)$ \\
\hline$c(\AA)$ & $24.4592(6)$ & $40.358(3)$ & $39.818(2)$ & $21.502(1)$ \\
\hline$\alpha$, deg & 90 & 90 & 90 & $82.539(2)$ \\
\hline$\beta$, deg & 90 & 99.313(1) & $99.769(1)$ & $89.719(2)$ \\
\hline$\gamma$, deg & 90 & 90 & 90 & $73.093(2)$ \\
\hline$V\left(\AA^{3}\right)$ & $7071.0(3)$ & $9511(1)$ & $9431.0(6)$ & $2628.0(2)$ \\
\hline$Z$ & 8 & 4 & 4 & 2 \\
\hline$D_{\mathrm{c}}\left(\mathrm{g} \mathrm{cm}^{-3}\right)$ & 1.506 & 1.344 & 1.347 & 1.338 \\
\hline$\mu\left(\mathrm{mm}^{-1}\right)$ & 0.427 & 0.568 & 0.415 & 0.521 \\
\hline$T(\mathrm{~K})$ & $90.0(1)$ & $90.0(1)$ & $90.0(1)$ & $90.0(1)$ \\
\hline $\max 2 \theta, \operatorname{deg}$ & 58.0 & 50.0 & 56.5 & 60.80 \\
\hline absorption correction & SADABS 2.05 & SADABS 2.05 & none & none \\
\hline reflections measured & 78420 & 44418 & 30926 & 40113 \\
\hline unique reflns ( $\left.\mathrm{R}_{\text {int }}\right)$ & $17004(0.035)$ & $8369(0.078)$ & $10602(0.046)$ & $14542(0.122)$ \\
\hline reflns $F>4 \sigma(F)$ & 14359 & 6552 & 8264 & 6511 \\
\hline parameters refined & 1087 & 641 & 641 & 721 \\
\hline $\mathrm{R}_{1}[F>4 \sigma(F)]$ & 0.045 & 0.052 & 0.037 & 0.082 \\
\hline $\mathrm{wR}_{2}$ & 0.126 & 0.109 & 0.098 & 0.235 \\
\hline GOF & 1.060 & 1.079 & 1.043 & 0.983 \\
\hline extinction coefficient & none & $0.00125(6)$ & $0.00176(8)$ & none \\
\hline
\end{tabular}

with the $\mathrm{Zn}$ atom by a $6-6$ bond [the $\mathrm{Zn} \cdots \mathrm{C}\left(\mathrm{C}_{60}\right)$ distances are 3.094-3.399 Å, dashed lines in Figure 3] and with nitrogen atoms of ZnTPP the $\mathrm{N} \cdots \mathrm{C}\left(\mathrm{C}_{60}\right)$ distances are $3.116-3.456 \AA$ ] . Each $\mathrm{C}_{60}$ also has van der Waals C...C contacts with toluene molecules within the columns (3.251-3.402 $\AA$ ).

Previously, only one crystal structure of pyrazine linked iron(II) octaethylporphyrin $[\mathrm{FeOEP}]_{2} \cdot \operatorname{Prz}$ was determined. ${ }^{11 a}$ The molecular structure of the (ZnTPP $)_{2}$. Prz dimer in the complex with $\mathrm{C}_{60}$ is essentially different from that of $[\mathrm{FeOEP}]_{2} \cdot$ Prz. Porphyrin planes are not parallel to each other and are inclined at an angle of $30.3^{\circ}$ without mutual rotation with respect to each other (the dihedral angle between them is $-0.3^{\circ}$ ). One of the Prz nitrogens forms a $\mathrm{Zn} \cdots \mathrm{N}$ bond arranged parallel to the Prz plane (the dihedral angle between this bond and the Prz plane is $2.3^{\circ}$ ). The other nitrogen forms a bent $\mathrm{Zn} \cdots \mathrm{N}$ bond (Figure 3 ). In this case, the corresponding angle is $18.6^{\circ}$ and makes an almost trigonal pyramid environment for the nitrogen atom [the sum of its bond angles is $357.0(6)^{\circ}$. The $\mathrm{Zn} \cdots \mathrm{N}(\mathrm{Prz})$ contacts are shorter for a parallel arrangement of $\mathrm{Zn} \cdots \mathrm{N}(\mathrm{Prz})$ bond than for a bent bond (2.179 and $2.211 \AA$, respectively). The ZnTPP macrocycles in the dimer are planar with $\mathrm{Zn}$ 


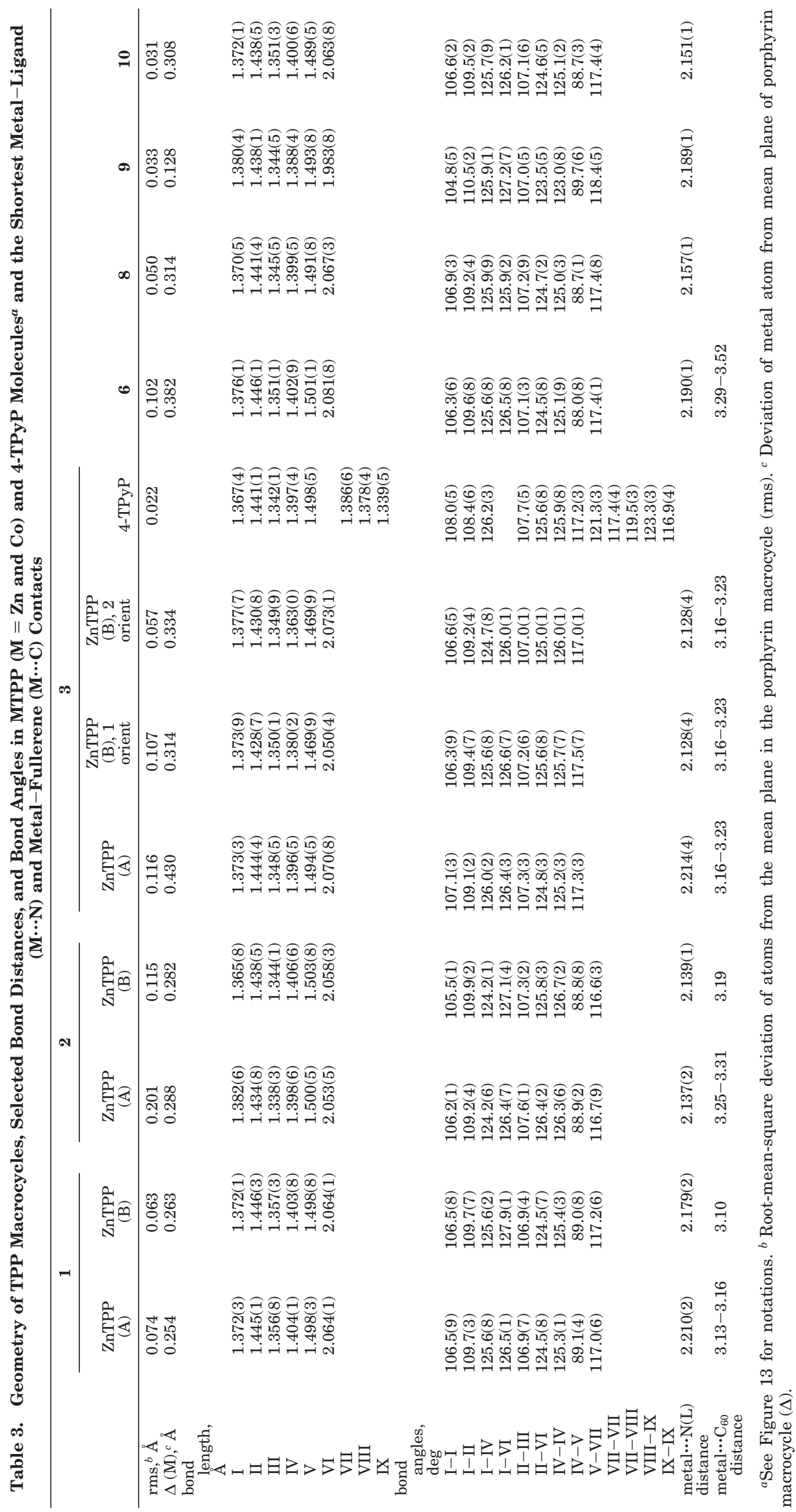




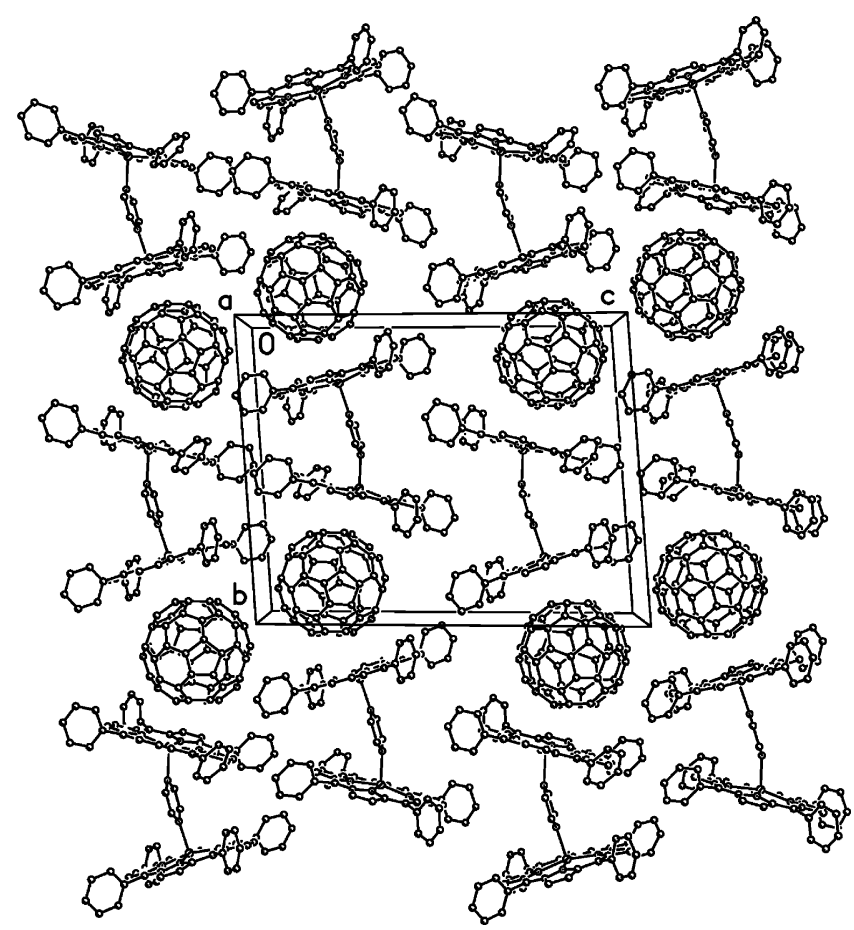

Figure 2. Packing motif of $(\mathrm{ZnTPP})_{2} \cdot \operatorname{Prz}$ dimers and $\mathrm{C}_{60}$ molecules in $\mathbf{1}$. View is along the $a$-axis. Toluene and benzonitrile molecules are not depicted for clarity.

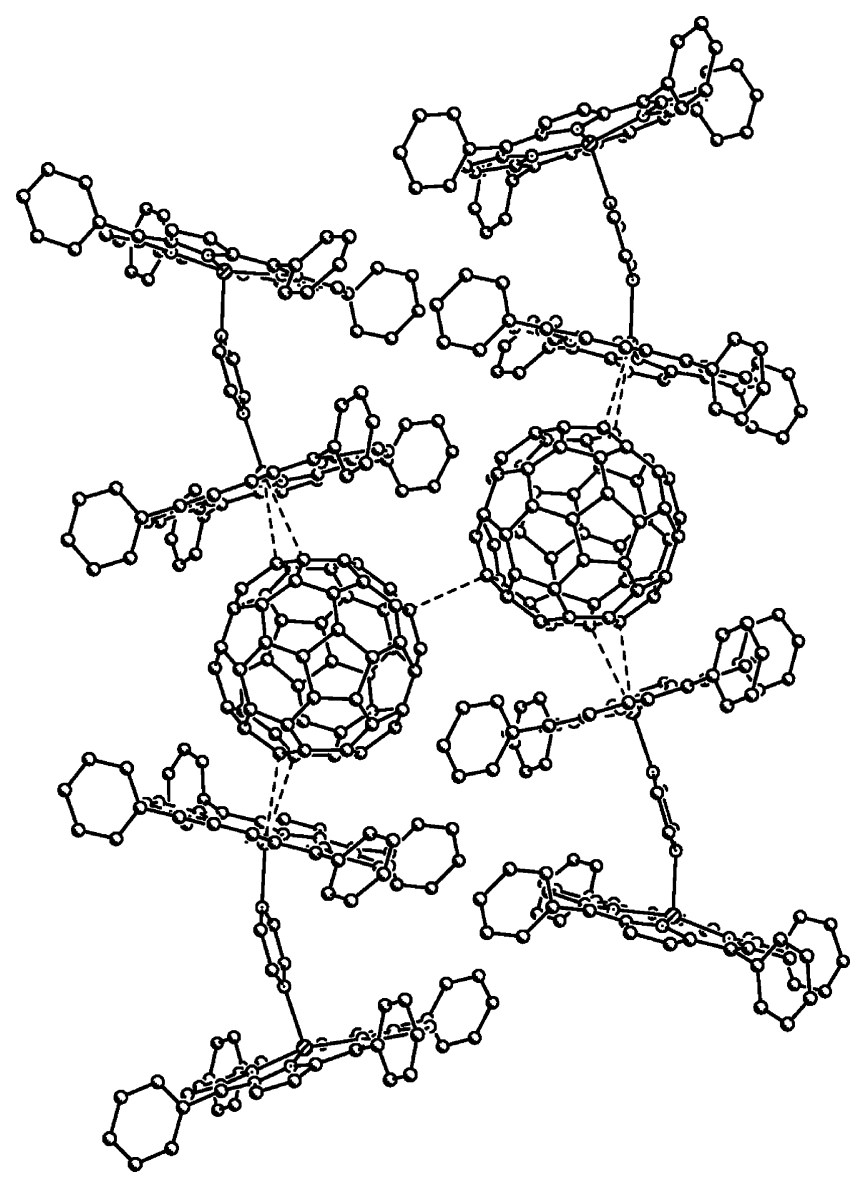

Figure 3. Van der Waals contacts between $(\mathrm{ZnTPP})_{2} \cdot \operatorname{Prz}$ and $\mathrm{C}_{60}$ units in $\mathbf{1}$ (dashed lines).

atoms displaced by 0.254 and $0.263 \AA$ from the mean plane of the porphyrin macrocycle toward Prz.

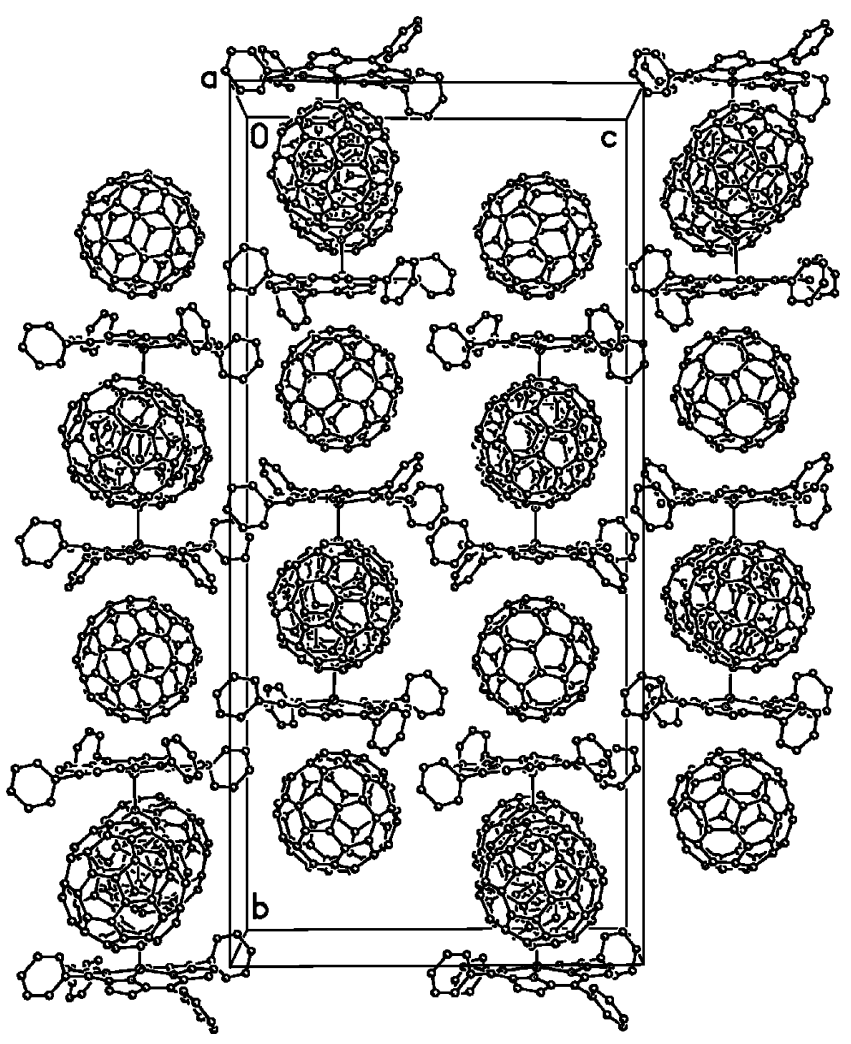

Figure 4. Packing motif of $(\mathrm{ZnTPP})_{2} \cdot \mathrm{BPy}$ dimers and $\mathrm{C}_{60}$ molecules in $\mathbf{2}$. View is along the $a$-axis. Toluene molecules are not depicted for clarity.

$\left[(\mathrm{ZnTPP})_{2} \cdot \mathbf{B P y}\right] \cdot\left(\mathrm{C}_{60}\right)_{2} \cdot\left(\mathrm{C}_{6} \mathrm{H}_{5} \mathrm{CH}_{3}\right)_{4}$ (2). The molecules in $\mathbf{2}$ form a three-dimensional (3D) packing with isolated fullerene molecules. $(\mathrm{ZnTPP})_{2} \cdot \mathrm{BPy}$ dimers and fullerene molecules alternate along the $b$-axis, whereas BPy ligands and fullerene molecules alternate along the $a$-axis (Figure 4$)$. Each $(\mathrm{ZnTPP})_{2} \cdot \mathrm{BPy}$ dimer has four fullerene neighbors (Figure 5). Two of them are located in an axial position to ZnTPP and form van der Waals contacts with a porphyrin macrocycle by a $5-6$ bond (dashed lines in Figure 5). The $\mathrm{Zn}$ and N(ZnTPP)... $\mathrm{C}\left(\mathrm{C}_{60}\right)$ contacts are $3.190-3.310$ and $3.062-3.170 \AA$, respectively (the sum of van der Waals radii of $\mathrm{N}$ and $\mathrm{C}$ atoms is $3.210 \AA) .{ }^{16}$ The intramolecular $\mathrm{N} \cdot \cdots \mathrm{N}$ distance of $7.1 \AA$ in BPy results in $11.372 \AA$ separation between porphyrin planes, which allows the fullerene molecules to be incorporated between them. Two other fullerene molecules form van der Waals C...C contacts with the central fragment of BPy (3.145-3.408 A). Probably because of these contacts, the torsion angle between the planes of two pyridine rings of $\mathrm{BPy}$ is only $14.3(1)^{\circ}$, whereas in the fullerene-free dimer $\left[(\mathrm{ZnTPP})_{2} \cdot \mathrm{BPy}\right]^{\cdot}$ $\left(\mathrm{C}_{6} \mathrm{H}_{5} \mathrm{CN}\right)_{4}(8)$ it is noticeably larger $\left(44.9(4)^{\circ}\right)$.

The cocrystallization with $\mathrm{C}_{60}$ molecules changes the geometry of the $(\mathrm{ZnTPP})_{2} \cdot \mathrm{BPy}$ dimer relative to that of pristine dimer in $\mathbf{8}$. Porphyrin molecules are no longer planar and have saddle conformation (the rms deviations are 0.201 and $0.115 \AA$ in $\mathbf{2}$ and only $0.05 \AA$ in 8 ). Although nitrogen atoms are still in the plane of a porphyrin macrocycle, zinc atoms are displaced by 0.288 and $0.282 \AA$ toward BPy. The porphyrin planes are located almost above each other (the shift is only 0.520 $\AA$ ). This makes both $\mathrm{Zn} \cdots \mathrm{N}(\mathrm{BPy})$ bonds nearly parallel to the planes of the Py rings and perpendicular to the 


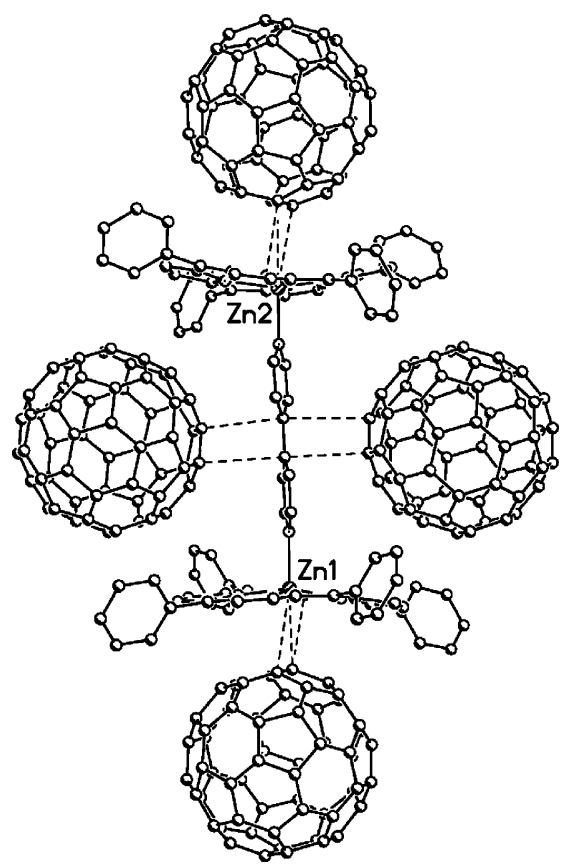

Figure 5. Van der Waals contacts between $(\mathrm{ZnTPP})_{2} \cdot \mathrm{BPy}$ and $\mathrm{C}_{60}$ units in $\mathbf{2}$ (dashed lines).

planes of four nitrogen atoms of ZnTPP (the corresponding angles are $1.8^{\circ}$ and $1.2^{\circ}$ for $\mathrm{Zn} 1$ and $\mathrm{Zn} 2$, respectively). The $\mathrm{Zn} \cdots \mathrm{N}$ (BPy) distances are 2.137 (Zn1) and 2.139 (Zn2) A.

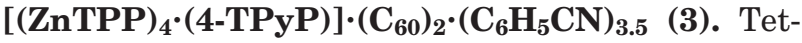
radentate $4-\mathrm{TPyP}$ and $\mathrm{ZnTPP}$ molecules form an unusual $(\mathrm{ZnTPP})_{4} \cdot(4-\mathrm{TPyP})$ pentamer stabilized in the solid state by the cocrystallization with $\mathrm{C}_{60}$ molecules (Figure 6). Each pentamer forms van der Waals contacts with four $\mathrm{C}_{60}$ molecules via the ZnTPP macrocycles. These aggregates are packed in belts as shown in Figure 7. The neighboring $(\mathrm{ZnTPP})_{4} \cdot(4-\mathrm{TPyP})$ pentamers have two common $\mathrm{C}_{60}$ molecules in the belt, and because of this, each $\mathrm{C}_{60}$ molecule forms van der Waals contacts with two ZnTPP molecules belonging to adjacent pentamers. The $\mathrm{Zn}$ and $\mathrm{N}(\mathrm{ZnTPP}) \cdots \mathrm{C}\left(\mathrm{C}_{60}\right)$ distances lie in the 3.16-2.23 and 2.96-3.23 $\AA$ ranges. Such distances are typical for other molecular complexes of N-coordinated $\mathrm{ZnTPP}$ with fullerenes ${ }^{5 \mathrm{~d}}$ and indicate the absence of noticeable metal $\cdots \mathrm{C}_{60}$ interaction. Fullerene molecules aggregate in pairs (Figure 7). Fullerenes from one pair belong to two different belts and are located at a center-to-center distance of $9.95 \AA$ with the shortest intermolecular $\mathrm{C} \cdot \mathrm{C}$ C contact of $3.27 \AA$. The belts arrange in such a way that each $\mathrm{C}_{60}$ molecule encapsulated by two ZnTPP ones is located either over or under the box of $(\mathrm{ZnTPP})_{4} \cdot(4-\mathrm{TPyP})$ pentamers. However, the $\mathrm{C}_{60}$ molecule is located too far from the 4-TPyP plane to form van der Waals contacts $\left(\mathrm{C}, \mathrm{N}(4-\mathrm{TPyP}) \cdots \mathrm{C}\left(\mathrm{C}_{60}\right)>\right.$ 6 Å) (Figure 6).

The molecular structure of $(\mathrm{ZnTPP})_{4} \cdot(4-\mathrm{TPyP})$ pentamer is shown in Figure 6. The macrocycles of oppositely located ZnTPP molecules are parallel in contrast to $(\mathrm{ZnTPP})_{2} \cdot$ Prz dimers in 1 . The ZnTPP molecule A forms a $\mathrm{Zn}-\mathrm{N}(\mathrm{Py})$ bond $2.214 \AA$ long, which is bent relative to the Py plane with a corresponding dihedral angle of $33^{\circ}$. On the contrary, the disordered ZnTPP molecule $\mathbf{B}$ forms an almost parallel $\mathrm{Zn}-\mathrm{N}(\mathrm{Py})$ bond $2.128 \AA$ long and a dihedral angle with the Py plane of $4.5^{\circ}$. It is interesting that previously described fullerene-free $(\mathrm{ZnTPP})_{2} \cdot(4-\mathrm{TPyP})$ trimers have only bent $\mathrm{Zn} \cdots \mathrm{N}(\mathrm{Py})$ bonds $2.197 \AA$ long. ${ }^{11 \mathrm{~d}}$ The porphyrin macrocycle of the $\mathrm{ZnTPP}$ molecule $\mathbf{A}$ has noticeable saddlelike deviations (the rms deviation of the atoms from the mean plane in the porphyrin macrocycle is $0.116 \AA$ ), whereas the ZnTPP molecule $\mathbf{B}$ is almost planar with small saddle-like deviations (the rms deviations are 0.0107-0.057 $\AA$ for different orientations of molecule B). The deviations for the ZnTPP molecule $\mathbf{A}$ are, however, smaller than those for saddle-shaped metal(II) tetraphenylporphyrins in solvent-free complexes with $\mathrm{C}_{60}$ : $0.263 \AA$ in $(\mathrm{CuTPP})_{2} \cdot \mathrm{C}_{60}$ (CuTPP: copper(II) tetraphenylporphyrin $^{9 \mathrm{a}}$ or $0.216 \AA$ in $\mathrm{CoTMPP} \cdot \mathrm{C}_{60}$ (CoTMPP: cobalt(II) tetrakis( $p$-methoxyphenyl)porphyrin).9d Zinc atoms are displaced from the mean plane of the porphyrin macrocycle toward the Py ligand by 0.430 (molecule A), and 0.314 and $0.334 \AA$ (two orientations of molecule B). These values are close to those for pyridine-coordinated $\mathrm{ZnTPP}$ in the complexes with $\mathrm{C}_{60}$ and $\mathrm{C}_{70}(0.435 \text { and } 0.433 \AA \text {, respectively })^{9 \mathrm{a}}$ and larger than in the $(\mathrm{ZnTPP})_{2} \cdot(4-\mathrm{TPyP})$ trimer $(0.27 \AA) .{ }^{11 \mathrm{~d}}$

$[\mathbf{Z n T P P} \cdot \mathbf{T H F}]_{2} \cdot\left(\mathbf{C}_{60}\right)_{6.4} \cdot\left(\mathbf{C}_{6} \mathbf{H}_{5} \mathbf{C l}\right)$ (4). The complex crystallizes in a monoclinic lattice with unusual $3 \mathrm{D}$ packing and a close arrangement of fullerene molecules (Figure 8). Each fullerene molecule in such packing has from three to six neighbors. Two crystallographically independent ZnTPP.THF units form van der Waals contacts with six and eight fullerene molecules. Four fullerene molecules are symmetrically positioned on the one side of ZnTPP around coordinated THF. Other fullerene molecules are positioned on the opposite side of ZnTPP. As this takes place, one fullerene molecule is located close to the $\mathrm{ZnN}_{4}$ fragment of porphyrin and the other ones form van der Waals contacts with phenyl rings of ZnTPP. Unfortunately, due to complete disorder and partial occupancy of one fullerene molecule, it is impossible to refine this crystal structure well. Because of this, we do not present distances and angles for this crystal structure.

[Zn'TPP.TMDAE] $\cdot \mathbf{C}_{60} \cdot\left(\mathrm{C}_{6} \mathrm{H}_{6}\right)_{0.7} \cdot\left(\mathrm{C}_{6} \mathrm{H}_{5} \mathrm{Cl}\right)_{0.3}$ Monomeric ZnTPP.TMDAE units form a cage structure with large channels passing along the $a$-axis. The channels accommodate fullerene molecules arranged in zigzag chains because the TMDAE ligands protrude inside the channels. These chains are completely encapsulated by the ZnTPP.TMDAE units (the walls of each channel are built of four ZnTPP.TMDAE units) and do not interact with each other (Figure 9). The $\mathrm{C}_{60}$ molecules have only two neighbors in the chain with a center-to-center distance of $10.01 \AA$. Solvent $\mathrm{C}_{6} \mathrm{H}_{6}$ and $\mathrm{C}_{6} \mathrm{H}_{5} \mathrm{Cl}$ molecules occupy cavities in a zigzag arrangement of fullerenes adjacent to the TMDAE ligand.

Although TMDAE is a bidentate ligand, ZnTPP is coordinated only to one of two TMDAE nitrogens (Figure 10 ), while the other nitrogen atom is freely located between two fullerene molecules (Figure 9). The ZnTPP molecule forms a $\mathrm{Zn}-\mathrm{N}$ (TMDAE) bond 2.190 ^ long, which is virtually perpendicular to the plane of four TPP nitrogen atoms, the $\mathrm{N}(\mathrm{TPP})-\mathrm{Zn}-\mathrm{N}$ (TMDAE) bond angles being $87.7(1)-88.9(1)^{\circ}$. The bonding displaces $\mathrm{Zn}$ by $0.382 \AA$ toward TMDAE. Both $\mathrm{N}$ atoms of TMDAE are arranged in almost perfect trans conformation with a torsion $\mathrm{N}-\mathrm{C}-\mathrm{C}-\mathrm{N}$ angle of $172.1(3)^{\circ}$. 


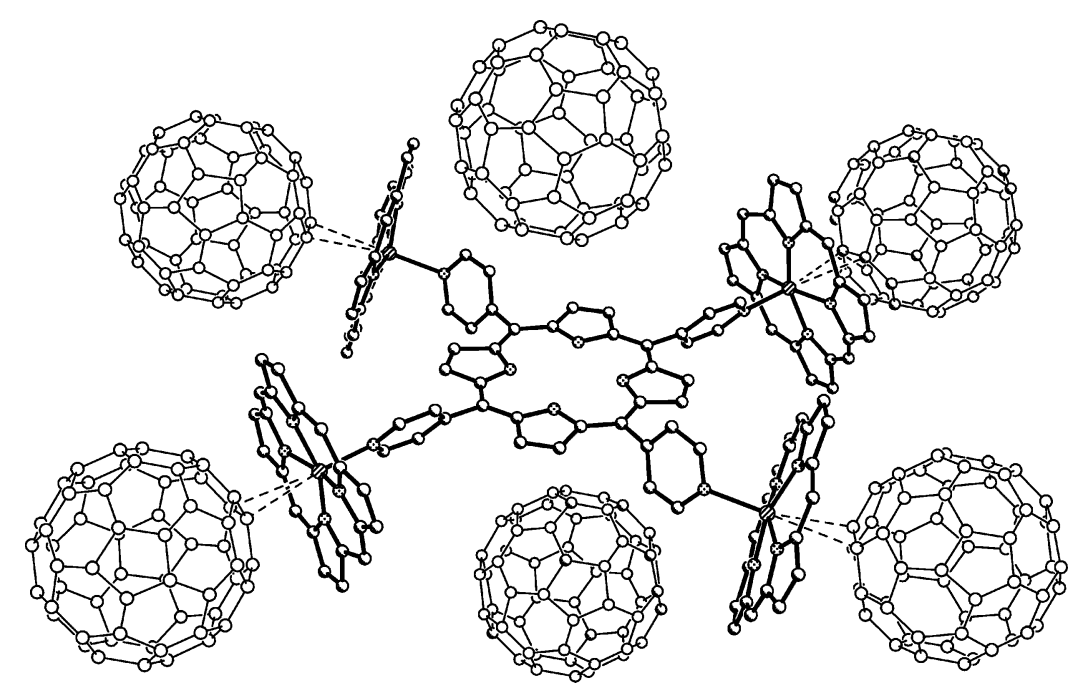

Figure 6. Van der Waals contacts (dashed lines) between (ZnTPP) ${ }_{4} \cdot(4-\mathrm{TPyP})$ pentamer and $\mathrm{C}_{60}$ molecules in 3 (dashed lines). Only one orientation with major occupancy is depicted for disordered $\mathrm{C}_{60}$ and $\mathrm{ZnTPP}(\mathrm{B})$ molecules. Benzonitrile and phenyl substituents of ZnTPP are omitted.

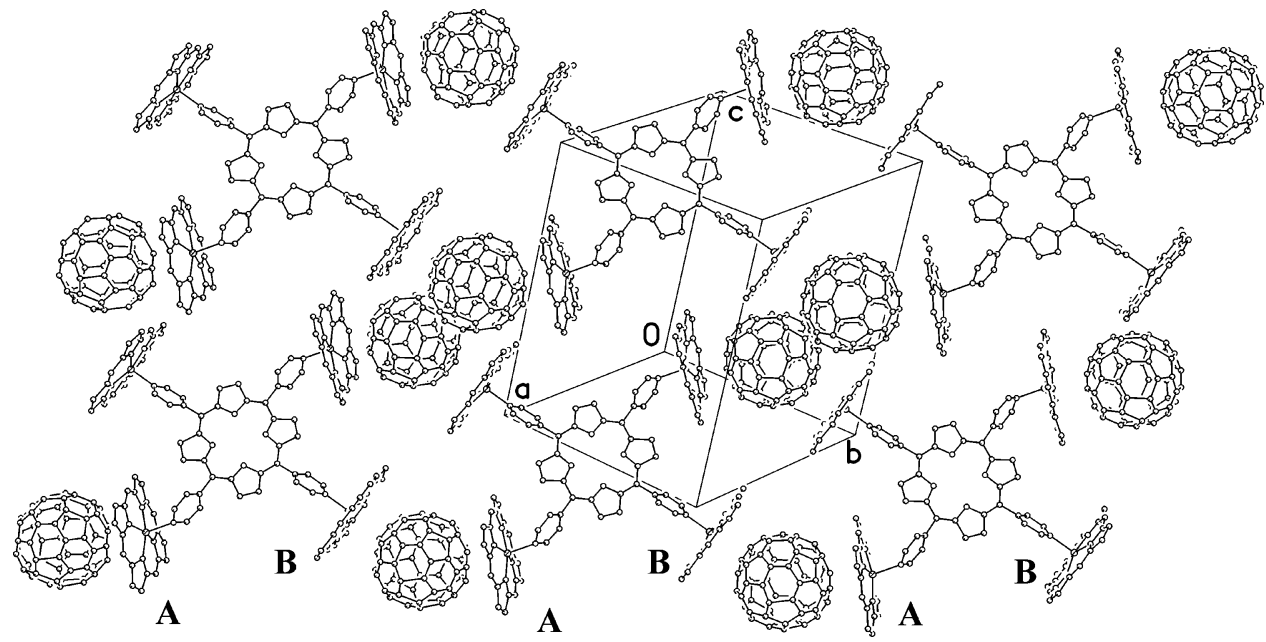

Figure 7. View of the crystal structure of 3 on the belts of $(\mathrm{ZnTPP})_{4} \cdot(4-\mathrm{TPyP})$. Two belts are shown on different levels. Only one orientation with major occupancy is depicted for disordered $\mathrm{C}_{60}$ and $\mathrm{ZnTPP}(\mathrm{B})$ molecules. Benzonitrile and phenyl substituents of $\mathrm{ZnTPP}$ are omitted.

Coordination with TMDAE produces a slightly concave shape of the ZnTPP macrocycle suitable for effective packing with spherical fullerene molecules. As this takes place, $\mathrm{Zn}$ atom forms close contacts with a fivemembered ring of $\mathrm{C}_{60}$ (the $\mathrm{Zn}$ and $\mathrm{N} \cdots \mathrm{C}\left(\mathrm{C}_{60}\right)$ distances are 3.29-3.52 and 3.09-3.41 $\AA$, respectively). Another oppositely located ZnTPP molecule also forms van der Waals contacts with the $\mathrm{C}_{60}$ molecule by a double bond of a five-membered ring of the porphyrin macrocycle (the C $\cdots$ C contacts lie in the 3.232-3.362 A range).

$\left[(\mathrm{ZnTPP})_{2} \cdot \mathbf{B P y}\right] \cdot\left(\mathrm{C}_{6} \mathrm{H}_{5} \mathrm{CN}\right)_{4}(\mathbf{8}) .8$ (Figure 11) is isostructural to $\left[(\mathrm{ZnTPP})_{2} \cdot \mathrm{BPy}\right] \cdot\left(\mathrm{C}_{6} \mathrm{H}_{5} \mathrm{NO}_{2}\right)_{4} 11 \mathrm{c}$ and $\left[(\mathrm{ZnTPP})_{2} \cdot \mathrm{BPy}\right] \cdot\left(\mathrm{C}_{6} \mathrm{H}_{5} \mathrm{CH}_{3}\right)_{4},{ }^{11 \mathrm{~g}}$ where the positions of nitrobenzene or toluene molecules are occupied by benzonitrile ones.

The porphyrin plane is almost flat with the $\mathrm{Zn}$ atom displaced by $0.314 \AA$ toward BPy. The $\mathrm{Zn}-\mathrm{N}(\mathrm{BPy})$ bond is slightly bent $\left(83^{\circ}\right)$ with respect to the plane of nitrogen atoms of ZnTPP. This bending is probably a result of a $1.56 \AA$ shift of the porphyrin macrocycles with respect to each other in the parallel planes. Two of four $\mathrm{C}_{6} \mathrm{H}_{5-}$ $\mathrm{CN}$ molecules occupy free axial positions in the ZnTPP molecules. Thus, hydrogen of $\mathrm{C}_{6} \mathrm{H}_{5} \mathrm{CN}$ forms a close contact with zinc $(\mathrm{H} \cdots \mathrm{Zn}$ distance is $2.946 \AA)$. In the fullerene containing complex $\mathbf{2}$ these axial positions are occupied by $\mathrm{C}_{60}$ molecules.

$\left[(\mathrm{CoTPP})_{2} \cdot \mathrm{BPy}\right] \cdot\left(\mathrm{C}_{6} \mathrm{H}_{5} \mathrm{CN}\right)_{4}(\mathbf{9}) .9$ is isostructural to 8 (Figure 11) and previously described [(CoTPP $\left.)_{2} \cdot \mathrm{BPy}\right] \cdot$ $\left(\mathrm{C}_{6} \mathrm{H}_{5} \mathrm{NO}_{2}\right)_{4},{ }^{11 \mathrm{c}}$ which contains nitrobenzene molecules instead of benzonitrile molecules. The porphyrin plane is flat with the cobalt atom displaced by $0.128 \AA$ toward BPy. This shift is essentially smaller than those in the ZnTPP containing complexes $(0.314-0.430 \AA)$. Interestingly, the $\mathrm{Co}-\mathrm{N}(\mathrm{BPy})$ bond is slightly inclined to the normal to the porphyrin plane. The $\mathrm{N}(\mathrm{CoTPP})-\mathrm{Co}-$ $\mathrm{N}(\mathrm{CoTPP})$ bond angles are 97.24(5)-98.64(4) ${ }^{\circ}$. This inclination results in the bending of the BPy ligand itself. Thus, the angle between the $\mathrm{Co}-\mathrm{N}(\mathrm{BPy})$ bond and the symmetrically equivalent $\mathrm{Co}-\mathrm{N}(\mathrm{BPy})$ bond is $7.0^{\circ}$. The Py planes of BPy are not parallel with respect to each other similar to 8 and form a torsion angle of 44.1$(2)^{\circ}$. Both free axial positions of CoTPP in the dimer are occupied by $\mathrm{C}_{6} \mathrm{H}_{5} \mathrm{CN}$ molecules, which form short $\mathrm{H}$... Co van der Waals contact of the 2.800 A length. 


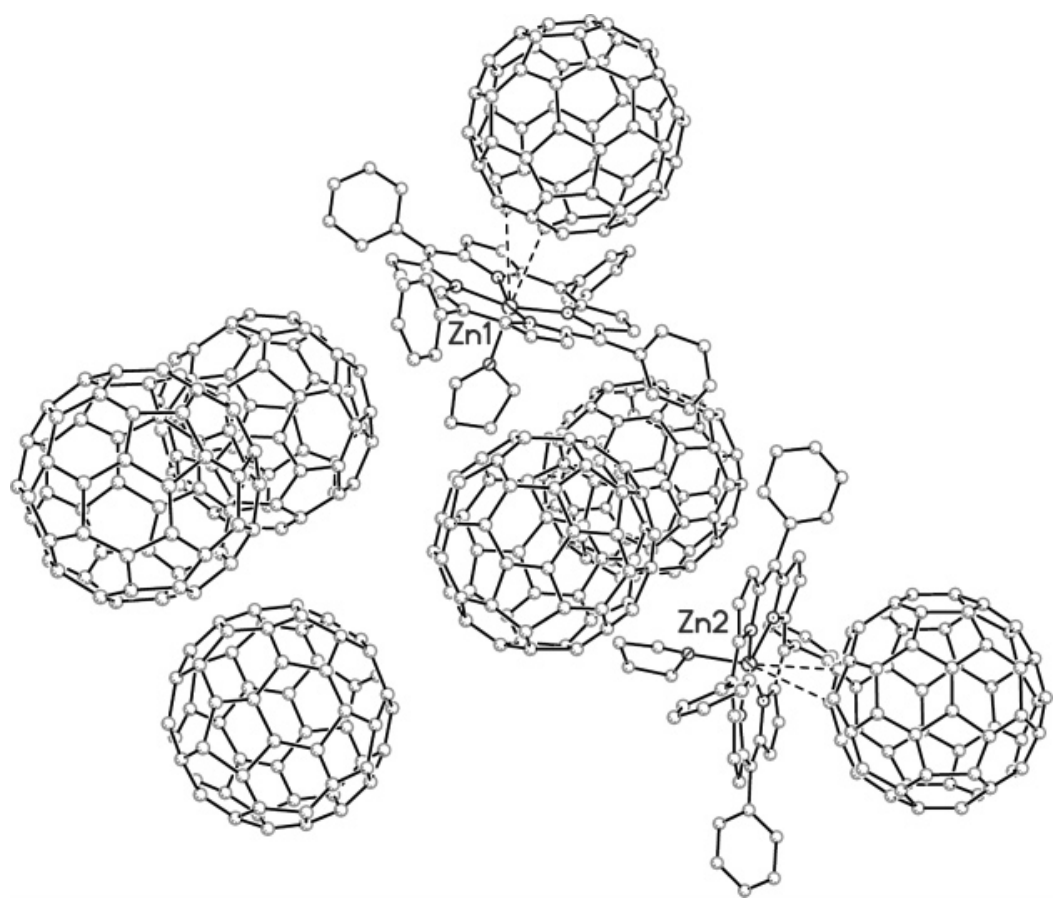

Figure 8. Fragment of the crystal structure of 4 showing crystallographically independent ZnTPP·THF units and $\mathrm{C}_{60}$ molecules.

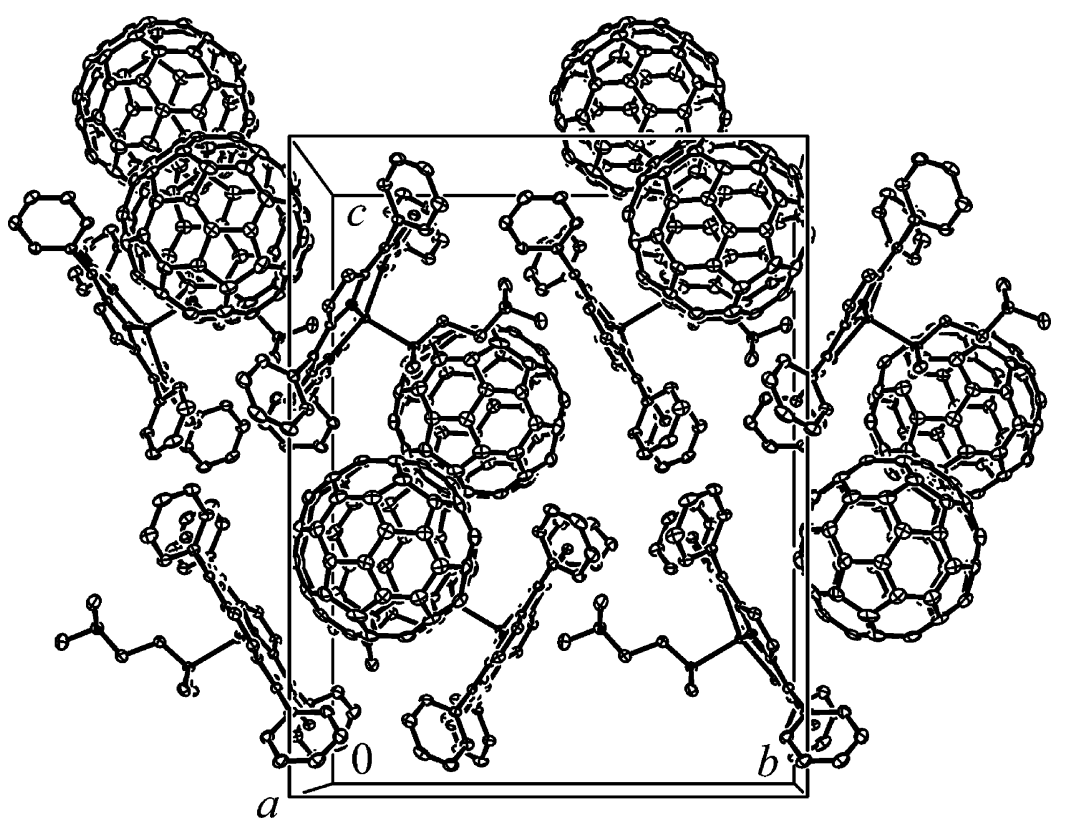

Figure 9. Packing of $\mathbf{6}$ (view along the $a$-axis and the zigzag chains of fullerene molecules are shown). Disordered solvent $\mathrm{C}_{6} \mathrm{H}_{6}$ and $\mathrm{C}_{6} \mathrm{H}_{5} \mathrm{Cl}$ molecules are not depicted for clarity.

$\left[(\mathrm{ZnTPP})_{2} \cdot \mathbf{B P E}\right] \cdot \mathbf{B P E} \cdot\left(\mathbf{C}_{6} \mathbf{H}_{5} \mathbf{C N}\right)_{3} \cdot \mathbf{C}_{6} \mathbf{H}_{5} \mathbf{M e}(\mathbf{1 0})$. The crystal structure of $\mathbf{1 0}$ (Figure 12) is different from that of the previously described $\left[(\mathrm{ZnTPP})_{2} \cdot \mathrm{BPE}\right] \cdot\left(\mathrm{C}_{6} \mathrm{H}_{5} \mathrm{NO}_{2}\right)_{3}$ complex obtained in nitrobenzene ${ }^{11 c}$ due to the presence of additional BPE and toluene molecules in the crystal structure. The porphyrin macrocycles are planar in the dimer with the $\mathrm{Zn}$ atom displaced by $0.308 \AA$ toward BPE. The pyridine fragments of BPE are coordinated to $\mathrm{Zn}$ atoms in a slightly bent fashion with the corresponding angle of $9.7^{\circ}$. The ZnTPP planes are parallel in the dimer with a $13.9 \AA$ separation between them. This allows the noncoordinated planar BPE ligand to be incorporated between the ZnTPP planes (Figure 12). $\mathrm{C}_{60}$ does not cocrystallize with the $(\mathrm{ZnTPP})_{2} \cdot \mathrm{BPE}$ dimer probably because the distance between ZnTPP planes in this dimer is too large to allow the effective incorporation of fullerene molecules inside the dimers. Free axial positions in $\mathrm{ZnTPP}$ are again occupied by $\mathrm{C}_{6} \mathrm{H}_{5}$ $\mathrm{CN}$ molecules with the shortest $\mathrm{Zn} \cdot \cdot \mathrm{H}$ contact of 3.01 $\AA$. Another $\mathrm{C}_{6} \mathrm{H}_{5} \mathrm{CN}$ molecule forms the $\mathrm{H} \cdots \pi$ contact $(2.89 \AA)$ with the aromatic system of the coordinated BPE ligand.

2. UV-Visible-NIR and IR Spectra of the Complexes. The UV-visible-NIR spectra of $\mathbf{1 - 7}$ in $\mathrm{KBr}$ pellets are a superposition of the spectra of the starting ZnTPP and $\mathrm{C}_{60}$ chromophores (Table 4). Figure 14 shows the spectrum of $\mathbf{2}$ and those of ZnTTP and $\mathrm{C}_{60}$ for comparison (other complexes have similar UV- 


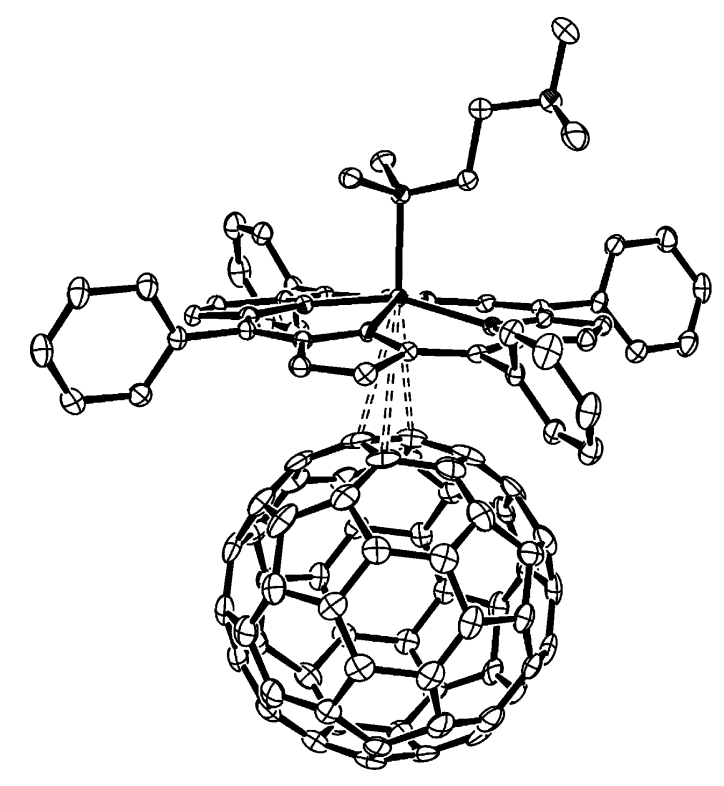

Figure 10. Van der Waals contacts between ZnTPP·TMDAE monomers and $\mathrm{C}_{60}$ molecules in $\mathbf{6}$ (dashed lines).

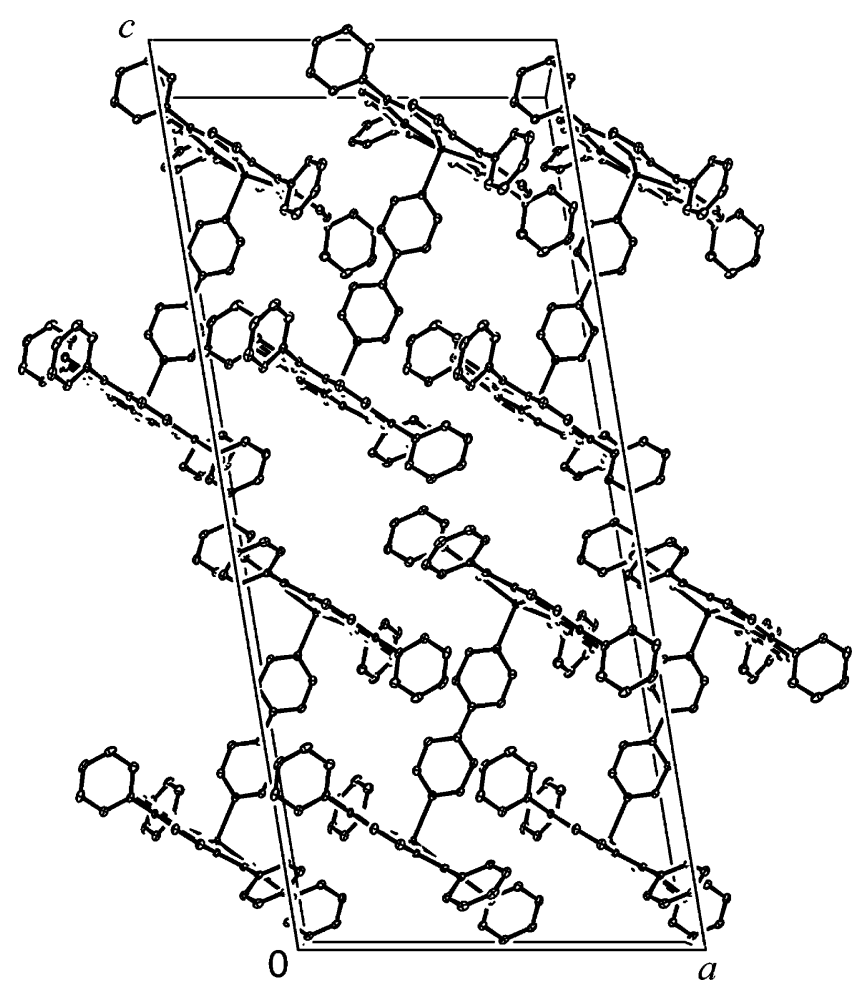

Figure 11. Packing motif of $(\mathrm{ZnTPP})_{2} \cdot \mathrm{BPy}$ dimers in 8 . View is along the $b$-axis.

visible-NIR spectra). The bands in the UV-range (denoted as 1 and 2 in Figure 14) are ascribed to neutral $\mathrm{C}_{60}$. These bands are blue shifted up to $16 \mathrm{~nm}$ relative to those of parent $\mathrm{C}_{60}(267$ and $346 \mathrm{~nm})$. The bands in the visible range denoted as 3, 4, and 5 in Figure 14 are attributed to ZnTPP. These bands are shifted at the coordination of the $\mathrm{N}$ - and O-containing ligands as well as the $\mathrm{C}_{60}$ molecules to ZnTPP. Thus, the Soret band at $431 \mathrm{~nm}$ (Figure 14, band 3) is shifted by $5-12 \mathrm{~nm}$ to the red side, whereas the Q-bands at 553 and $623 \mathrm{~nm}$ (Figure 14, bands 4 and 5) are shifted to the red (5-13 $\mathrm{nm})$ and the blue sides $(18-26 \mathrm{~nm})$, respectively.

In all fullerene-containing complexes (1-7) additional absorption in the visible range with the maxima at 760$820 \mathrm{~nm}$ can be attributed to CT from ZnTPP to the acceptor $\mathrm{C}_{60}$ molecule at the absorption of light quantum. Small shifts of these bands for the $\mathrm{ZnTPP} \cdot \mathrm{L}-\mathrm{C}_{60}$ complexes can be attributed to the additional effect of coordinated ligands on donor ability of the ZnTPP.L units (L: ligand). Exact values of ionization potentials for the $\mathrm{ZnTPP} \cdot \mathrm{L}$ units are absent to allow any correlation for this dependence. However, it is seen that the CT energies are the smallest for the 4-TPyP ligand, increase for diamine ligands, and are the highest for Prz and BPy ligands, which have the lowest donating ability.

The IR spectra of $\mathbf{1 - 7}$ (see Supporting Information) show all features of the components of the complexes. The position of $F_{1 u}(4)$ mode of $\mathrm{C}_{60}$ (at $1429 \mathrm{~cm}^{-1}$ ) in 1-2 and 4-5, which is sensitive to CT to the $\mathrm{C}_{60}$ molecule ${ }^{17}$, shows only small shifts (up to $3 \mathrm{~cm}^{-1}$ ), providing evidence of a neutral ground state of the complexes. The $F_{1 u}(4)$ band is split into three bands in $\mathbf{6}$ and $\mathbf{7}$ (at 1424, $1427,1429 \mathrm{~cm}^{-1}$ ) indicating the freezing of rotation of the $\mathrm{C}_{60}$ molecules in these complexes even at room temperature. ${ }^{18}$ Small shifts of the bands of the ZnTPP molecule observed in the spectra of $\mathbf{1 - 7}$ seem to be associated with changes in the geometry of ZnTPP rather than with $\mathrm{CT}$. Thus, according to the visibleNIR and IR spectra, $\mathbf{1}-\mathbf{7}$ can be classified as neutral CT complexes.

3. Peculiarities of the Formation of Fullerene C $_{60}$ Complexes with Supramolecular ZnTPP Assemblies. We obtained a series of new complexes of $\mathrm{C}_{60}$ with monomer, dimer, and pentamer supramolecular ZnTPP assemblies. To prepare these assemblies (D) we used mono, bi, and tertadentate ligands. Bidentate ligands of two types were used: those containing pyridine fragments (Prz, BPy, and BPE) and methyl substituted diamines (TMDAM, TMDAE, TMDAB, and TMDAH).

The possibility of the cocrystallization of $\mathrm{C}_{60}$ with supramolecular ZnTPP oligomers and the architecture of the cocrystals are dependent on a bidentate ligand length. The shortest Prz ligand (the intramolecular $\mathrm{N} \cdots \mathrm{N}$ distance is $2.78 \AA$ and the $\mathrm{Zn}$ to $\mathrm{Zn}$ distance in the dimer is $7.49 \AA$ ) forms a $(\mathrm{ZnTPP})_{2} \cdot \operatorname{Prz}$ dimer cocrystallized with $\mathrm{C}_{60}$ at a $\mathrm{D} / \mathrm{C}_{60}=1: 1$ molar ratio (1). Each porphyrin dimer in this structure has only two fullerene neighbors located in an axial position to ZnTPP (Figure 2). The shortest ligand among diamines, TMDAM, also forms a [(ZnTPP $\left.)_{2} \cdot \mathrm{TMDAM}\right]$ dimer cocrystallized with $\mathrm{C}_{60}$ at a $\mathrm{D} / \mathrm{C}_{60}=1: 1$ molar ratio (5).

The increased length of the diamine ligand TMDAE (the $\mathrm{N} \cdots \mathrm{N}$ distance is $3.81 \AA$ ) results in the cocrystallization of $\mathrm{C}_{60}$ with the ZnTPP.TMDAE monomer at a $\mathrm{D} / \mathrm{C}_{60}=1: 1$ molar ratio $(6)$. Related $\mathrm{ZnTPP} \cdot \mathrm{Py}$ monomers form complexes with fullerenes $\mathrm{C}_{60}$ and $\mathrm{C}_{70}$, however, at a $\mathrm{D} / \mathrm{C}_{60}=2: 1$ molar ratio. ${ }^{5 \mathrm{~d}}$

The use of longer BPy essentially increases the interplanar distance in the $(\mathrm{ZnTPP})_{2} \cdot \mathrm{BPy}$ dimer and allows the incorporation of fullerene molecules between the $\mathrm{ZnTPP}$ planes (the $\mathrm{Zn}$ to $\mathrm{Zn}$ distance in the dimer is $11.37 \AA$ ). In contrast to $\mathbf{1}$, each $(\mathrm{ZnTPP})_{2} \cdot \mathrm{BPy}$ dimer has four fullerene neighbors. Two of them are located in an axial position to ZnTPP (as well as in 1) and two other fullerene molecules form van der Waals contacts 


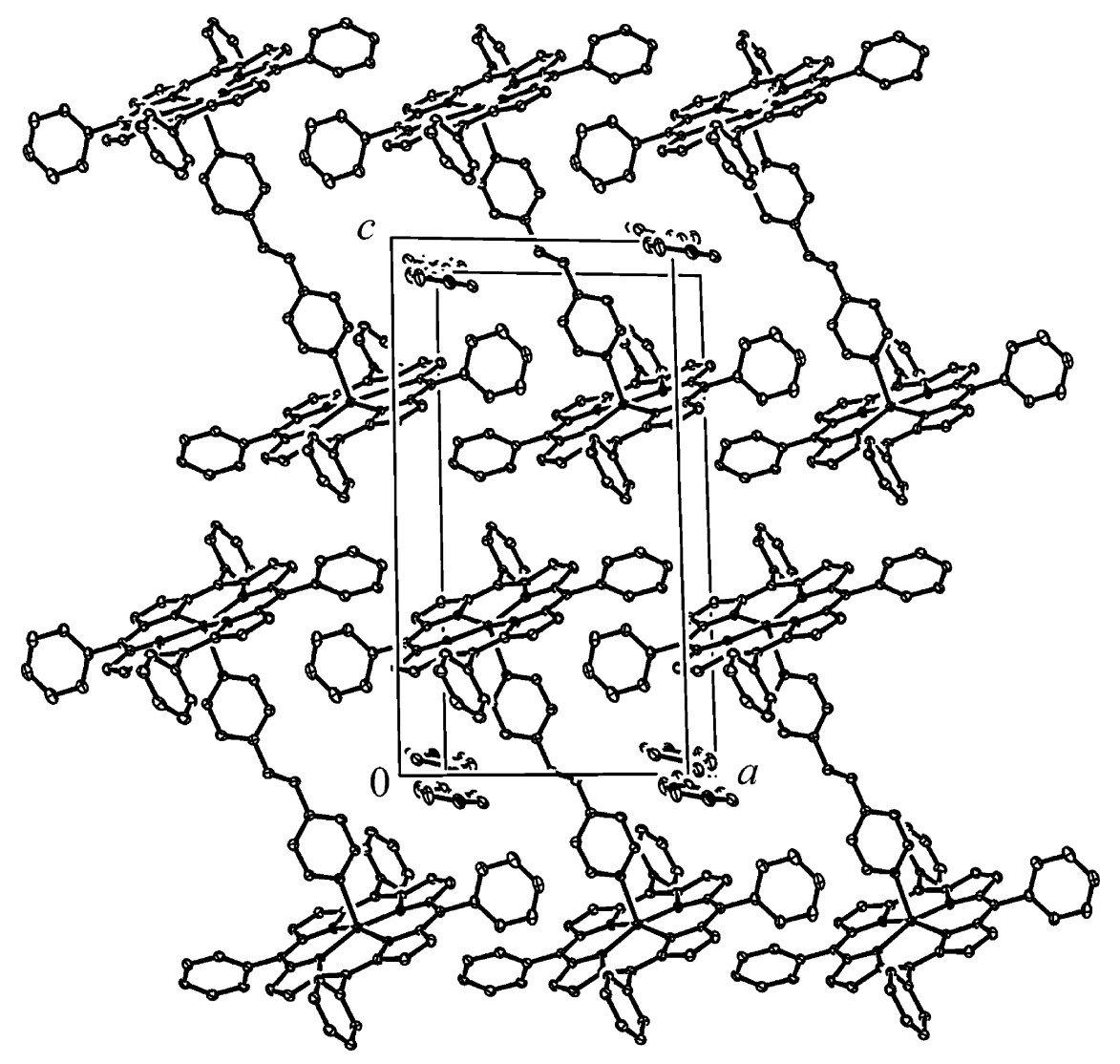

Figure 12. Packing motif of $(\mathrm{ZnTPP})_{2} \cdot \mathrm{BPE}$ dimers and BPE molecules in 10. View is along the $b$-axis.

Table 4. The UV-Visible-NIR Spectra for Starting

\begin{tabular}{|c|c|c|c|c|c|c|c|c|c|}
\hline \multirow[b]{3}{*}{ compd } & \multirow[b]{3}{*}{$\mathrm{C}_{60}, \mathrm{~nm}$} & & \multicolumn{6}{|c|}{ ZnTPP, nm } & \multirow{3}{*}{$\begin{array}{c}\text { CT bands } \\
\text { nm }\end{array}$} \\
\hline & & & \multicolumn{2}{|c|}{ Soret } & \multicolumn{4}{|c|}{ Q-bands } & \\
\hline & & & $\lambda_{1}$ & $\Delta^{a}$ & $\lambda_{2}$ & $\Delta$ & $\lambda_{3}$ & $\Delta$ & \\
\hline $\mathrm{C}_{60}$ & 267 & 346 & & & & & & & \\
\hline ZnTPP & & & 431 & & 553 & & 623 & & \\
\hline 1 & 263 & 330 & 442 & 11 & 566 & 13 & 605 & -18 & 760 \\
\hline 2 & 264 & 338 & 443 & 12 & 566 & 13 & 602 & -21 & 770 \\
\hline 3 & 259 & 332 & 436 & 5 & 560 & 7 & 600 & -23 & 820 \\
\hline 4 & 262 & 341 & 442 & 11 & 558 & 5 & 597 & -26 & 820 \\
\hline 5 & 260 & 333 & 439 & 8 & 565 & 12 & 603 & -20 & 780 \\
\hline 6 & 261 & 333 & 441 & 10 & 564 & 11 & 597 & -26 & 790 \\
\hline 7 & 259 & 336 & 438 & 7 & 563 & 10 & 599 & -24 & 780 \\
\hline
\end{tabular}

${ }^{a} \Delta-$ the shift of the band in the complex relative to parent ZnTPP.

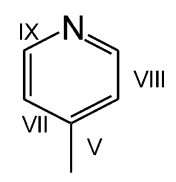

Py in 4-TPyP

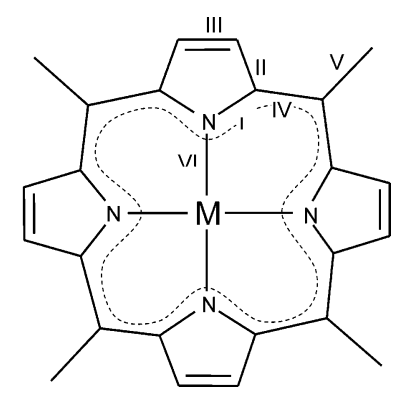

Figure 13. Notation of chemically equivalent bonds and bond angles in porphyrin moiety for Table 3.

with the central fragment of BPy (Figure 5). This is possible because the length of the BPy ligand (the $\mathrm{N}$ • $\cdot \mathrm{N}$ distance is $7.1 \AA$ ) is exactly equal to the diameter of the $\mathrm{C}_{60}$ sphere $\left(7.1 \AA\right.$ ). This yields complex 2 at a $\mathrm{D} / \mathrm{C}_{60}$

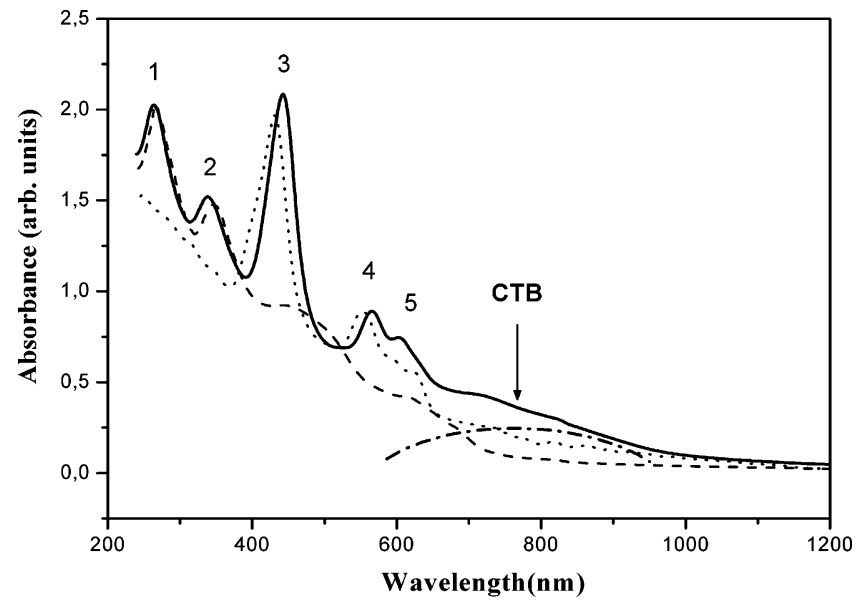

Figure 14. UV-visible-NIR spectra of 2 (full line), starting $\mathrm{ZnTPP}$ (dotted line), and $\mathrm{C}_{60}$ (dashed line) in a $\mathrm{KBr}$ matrix. The position of the CT band is shown by the arrow. For attribution of the bands of $1-5$, see the text.

$=1: 2$ molar ratio. Similarly, according to the composition of 6 with a longer diamine ligand, TMDAB forms the $(\mathrm{ZnTPP})_{2} \cdot \mathrm{TMDAB}$ dimer, which cocrystalizes with $\mathrm{C}_{60}$ at a $\mathrm{D} / \mathrm{C}_{60}=1: 2$ molar ratio (7). Probably, TMDAB is also long enough to incorporate $\mathrm{C}_{60}$ molecules between the ZnTPP planes in the dimer.

The further increase of the length of a bidentate ligand does not allow the formation of a complex with $\mathrm{C}_{60}$. Indeed, in case of the longest BPE (the $\mathrm{N} \cdots \mathrm{N}$ distance is $9.37 \AA$, and the TPP interplanar separation is about $14.26 \AA$ ) and TMDAH ligands, only fullerene free $(\mathrm{ZnTPP})_{2} \cdot \mathrm{BPE}(\mathbf{1 0})$ and $(\mathrm{ZnTPP})_{x} \cdot \mathrm{TMDAH}$ oligomers crystallize. Thus, the variation of the length of a 
coordination ligand used as a third component allows one to govern supramolecular architectures of fullereneporphyrin complexes in a crystal.

Initially, planar ZnTPP does not form a complex with $\mathrm{C}_{60}$ (on the contrary, $\mathrm{C}_{70}$ forms a complex with $\mathrm{ZnTPP}{ }^{5 b}$ ). Therefore, complexes of ZnTPP with $\mathrm{C}_{60}$ can be obtained only in the presence of a third component, which can coordinate to ZnTPP. Previously, two conformations of metal tetraphenylporphyrin molecules were observed in complexes with fullerenes. Solvent containing complexes of porphyrins have a nearly planar shape of a porphyrin microcycle, ${ }^{5}$ whereas in solvent-free complexes porphyrins adopt saddle-like conformations, and both forms can be obtained for the same porphyrin. ${ }^{5 c, d}$ The complexes discussed in the present paper adopt another slightly concave conformation of a porphyrin macrocycle, which was attained due to a $0.254-0.430 \AA$ displacement of a $\mathrm{Zn}$ atom toward a ligand. Such a conformation provides the surface suitable for the formation of shortened van der Waals contacts with nearly spherical fullerene molecules. In some cases, porphyrin macrocycles also have additional saddle-like deviations, which, however, in all cases are smaller than similar deviations in solvent-free porphyrin-fullerene complexes. Similar concave conformation of a porphyrin macrocycle is characteristic of covalently linked $\left(\mathrm{Fe}^{\mathrm{III}} \mathrm{TPP}\right)_{2} \mathrm{O}$ and $\left(\mathrm{Fe}^{\mathrm{III}} \mathrm{OEP}\right)_{2} \mathrm{O}$ dimers and some other pentacoordinated metalloporphyrins, which also cocrystallized with fullerenes. ${ }^{4,19}$ It should be noted that CoTPP with an essentially smaller displacement of the Co atom toward a ligand as in $\mathbf{9}$ does not form such supramolecular complexes with $\mathrm{C}_{60}$ in similar conditions in contrast to ZnTPP (up to now only the $\mathrm{C}_{60}$ complex with CoTPP. Py monomers was known ${ }^{5 d}$ ). The displacement of the $\mathrm{Zn}$ atom toward a ligand makes the $\mathrm{Zn} \cdots \mathrm{C}_{60}$ interaction weaker [the $\mathrm{Zn} \cdots \mathrm{C}\left(\mathrm{C}_{60}\right)$ distances are $3.10-3.29 \AA$ ] and only short $\mathrm{N} \cdots \mathrm{C}$ contacts are found in the $2.960-3.116$ $\AA$ range. The $\mathrm{Zn} \cdots \mathrm{C}\left(\mathrm{C}_{70}\right)$ distances in the $\mathrm{C}_{70}$ complex with planar ZnTPP are noticeably shorter $(2.89 \AA) .5 \mathrm{~b}$ These data show that although fullerenes form complexes with nearly planar porphyrin molecules, the concave shape of the porphyrin surfice is preferable for cocrystallization with them. Such concave surfaces have covalently bound porphyrin and dimers, double-decker porphyrins, and phthalocyanines.

The ligands form the $\mathrm{Zn} \cdots \mathrm{N}$ bonds, whose arrangement changes from a nearly parallel to an essentially bent one (up to $33^{\circ}$ ) relative to the ligand plane. Obviously, a parallel arrangemnt of the $\mathrm{Zn} \cdots \mathrm{N}$ bond provides a more effective overlapping of the orbitals of $\mathrm{Zn}$ and a ligand, and shorter $\mathrm{Zn} \cdots \mathrm{N}(\mathrm{L})$ bonds $(2.13-$ $2.19 \AA$ A lengths). The bending of the $\mathrm{Zn} \cdots \mathrm{N}(\mathrm{L})$ bond relative to a ligand plane provides longer $\mathrm{Zn} \cdots \mathrm{N}(\mathrm{L})$ bonds of a $2.21 \AA$ length. The type of binding is defined probably by packing factors rather than by peculiarities of a ligand itself. This is a reason for porphyrin dimers to have different conformations in the complexes with $\mathrm{C}_{60}$ as compared with the starting dimers. In one case, cocrystallization with $\mathrm{C}_{60}$ allows the stabilization of unusual (ZnTPP) ${ }_{4} \cdot(4-\mathrm{TPyP})$ pentamers in the solid state, which are unstable in the absence of fullerene. The $(\mathrm{ZnTPP})_{4} \cdot(4-\mathrm{TPyP})$ pentamers probably exist in solution, but in the solid state exceptional (ZnTPP) $)_{2} \cdot(4-\mathrm{TPyP})$ trimers are crystallized. ${ }^{11 \mathrm{~d}}$
Rapid singlet energy transfer was observed in the toluene solution containing fullerene $\mathrm{C}_{60}$ and some coordinated metalloporphyrin assemblies. ${ }^{12}$ Recently, it has been shown that photoinduced CT could also be realized in solid fullerene complexes with a neutral ground state. ${ }^{20}$ One of mechanisms, responsible for the generation of free charge carriers in fullerene complexes is direct CT from the donor to the $\mathrm{C}_{60}$ molecule. ${ }^{20}$ Concave porphyrin surface provides a better overlapping of $\pi$-orbitals of ZnTPP and $\mathrm{C}_{60}$ and, as a result, intense enough CT bands observed in the visible-NIR spectra of 1-7 at 760-820 nm. Previously studied $\mathrm{C}_{60}$ and $\mathrm{C}_{70}$ complexes with planar and saddle-shaped porphyrins showed the spectra, in which the CT bands were either less intense or even absent. ${ }^{5 c, d}$ Thus, supramolecular assemblies can be interesting by their photoactive properties.

Another extension of this work is the development of ionic multicomponent complexes of fullerenes based on supramolecular ZnTPP assemblies. As it was shown above, the complexes contain large cavities, which can accommodate small cations such as $\mathrm{Cr}^{\mathrm{I}}\left(\mathrm{C}_{6} \mathrm{H}_{6}\right)_{2}{ }^{+}$or $\mathrm{TDAE}^{\cdot+}$ to form $(\mathrm{ZnTPP} \cdot \mathrm{L})\left(\mathrm{D}^{+}\right)\left(\mathrm{C}_{60^{\circ-}}\right)$ complexes. Such complexes can possess interesting magnetic properties.

\section{Conclusion}

It was found that ZnTPP units slightly concaved by ligand coordination effectively cocrystallize with nearly spherical fullerene molecules to produce a variety of packing motifs. Fullerenes are packed in a 3D structure (4), 1D zigzag chains (6), pairs (1 and 3), and are isolated in 2. The length of a bidentate ligand defines the possibility of cocrystallization and supramolecular architectures of the $\mathrm{ZnTPP} \cdot \mathrm{L}-\mathrm{C}_{60}$ complexes, which can either have 1:1 or 1:2 compositions (porphyrin dimer/ fullerene) or form a 1:1 complex with monomeric ZnTPP. $\mathrm{L}$ units. Large ligands such as BPE and TMDAH prevent the formation of supramolecular complexes. The ligands form $\mathrm{Zn} \cdots(\mathrm{N})$ bonds nearly parallel to the plane of the ligand or this bond is bent up to $33^{\circ}$ relative to the ligand plane. The characteristic $\mathrm{Zn} \cdots \mathrm{N}(\mathrm{L})$ bond length is $2.13-2.19$ and $2.21 \AA$, respectively. The $\mathrm{Zn} \cdots \mathrm{C}\left(\mathrm{C}_{60}\right)$ distances are essentially longer $(3.10-3.29$ $\AA$ ) due to the displacement of the Zn atom toward the coordinating ligand. Complexes $\mathbf{1}-\mathbf{7}$ have quite intense CT bands at 760-820 $\mathrm{nm}$ depending on a ligand used, which indicate efficient overlapping between the ZnTPP chromophore and the acceptor $\mathrm{C}_{60}$ molecules. According to the visible-NIR and IR spectra, the complexes are molecular ones without $\mathrm{CT}$ in the ground state and are formed mainly by van der Waals forces.

The neutral ground state and the occurrence of intense enough CT bands provide potentially interesting photoactive properties of these compounds. The presence of large cavities allows the development of new ionic multicomponent complexes based on supramolecular ZnTPP.L- $\mathrm{C}_{60}$ complexes. Such ionic multicomponent complexes can potentially possess interesting magnetic properties.

Acknowledgment. The work was supported by the Linkage Grant of NATO Science Program, the Russian Program "Fullerenes and Atomic Clusters", Russian Foundation for Basic Research (Grants 03-03-32699a and 03-03-20003BSTC_a). 
Supporting Information Available: CIF files and tables of IR data for the starting compounds and for complexes 1-8 and $\mathbf{1 0}$ are available free of charge via the Internet at http:// pubs.acs.org.

\section{References}

(1) (a) Sariciftci, N. S.; Heeger, A. J. Handbook of Organic Conductive Molecules and Polymers; Nalwa, H. S., Ed.; John Wiley and Sons Ltd.: New York, 1997; Vol. 1, pp 414-457. (b) Gust, D.; Moore, T. A.; Moore A. L. Acc. Chem. Res. 2001, 34, 40-48. (c) Imahori, H.; Mori, Y.; Matano, Y. J. Photochem. Photobiol. C: Rev. 2003, 4, 51-83.

(2) (a) Guldi, D. M. Pure Appl. Chem. 2003, 75, 1069-1075. (b) Guldi, D. M. Chem. Soc. Rev. 2002, 31, 22-36. (c) ElKhouly, M. E.; Ito, O.; Smith, P. M.; D'Souza, F. J. Photochem. Photobiol. C: Rev. 2004, 5, 79-104.

(3) Loi, M. A.; Denk, P.; Hoppe, H.; Neugebauer, H.; Winder, C.; Meissner, D.; Brabec, C.; Sariciftci, N. S.; Gouloumis, A.; Vázquez, P.; Torres, T. J. Mater. Chem. 2003, 13, 700704 .

(4) (a) Olmstead, M. M.; Costa, D. A.; Maitra, K.; Noll, B. C.; Phillips, S. L.; Van Calcar, P. M.; Balch, A. L. J. Am. Chem. Soc. 1999, 121, 7090-7097. (b) Ishii, T.; Aizawa, N.; Kanehama, R.; Yamashita, M.; Sugiura, K.; Miyasaka, H. Coord. Chem. Rev. 2002, 226, 113-124.

(5) (a) Yudanova, E. I.; Konarev, D. V.; Gumanov, L. L.; Lyubovskaya, R. N. Russ. Chem. Bull. 1999, 48, 718-721. (b) Boyd, P. D. W.; Hodgson, M. C.; Rickard, C. E. F.; Oliver, A. G.; Chaker, L.; Brothers, P. J.; Bolskar, R. D.; Tham, F. S.; Reed, C. A. J. Am. Chem. Soc. 1999, 121, 10487-10485. (c) Konarev, D. V.; Neretin, I. S.; Slovokhotov, Y. L.; Yudanova, E. I.; Drichko, N. V.; Shul'ga, Y. M.; Tarasov, B. P.; Gumanov, L. L.; Batsanov, A. S.; Howard, J. A. K.; Lyubovskaya, R. N. Chem. Eur. J. 2001, 7, 2605-2616. (d) Konarev, D. V.; Kovalevsky, A. Y.; Li, X.; Neretin, I. S.; Litvinov, A. L.; Drichko, N. V.; Slovokhotov, Y. L.; Coppens, P.; Lyubovskaya, R. N. Inorg. Chem. 2002, 41, 3638-3646.

(6) (a) Sun, D.; Tham, F. S.; Reed, C. A.; Chaker, L.; Boyd, P. D. W. J. Am. Chem. Soc. 2000, 122, 10704-10705. (b) Sun, D.; Tham, F. S.; Reed, C. A.; Chaker, L.; Boyd, P. D. W. J. Am. Chem. Soc. 2002, 124, 6604-6612. (b) Zheng, J.-Y.; Tashiro, K.; Hirabayashi, Y.; Kinbara, K.; Saigo, K.; Aida, T.; Sakamoto, S.; Yamaguchi, K. Angew. Chem., Int. Ed. 2001, 40, 1858-1861.

(7) (a) Pénicaud, A.; Hsu, J.; Reed, C. A.; Koch, A.; Khemani, K. C.; Allemand, P.-M.; Wudl, F. J. Am. Chem. Soc. 1991, 113, 6698-6700. (b) Stinchcombe, J.; Pénicaud, A.; Bhyrappa, P.; Boyd, P. D. W.; Reed, C. A. J. Am. Chem. Soc. 1993, $115,5212-5217$.

(8) (a) Stevenson, S.; Rice, G.; Glass, T.; Harich, K.; Cromer, F.; Jordan, M. R.; Craft, J.; Hadju, E.; Bible, R.; Olmstead, M. M.; Maitra, K.; Fisher, A. J.; Balch, A. L.; Dorn, H. C. Nature 1999, 401, 55-57. (b) Olmstead, M. M.; de Bettencourt-Dias, A.; Duchamp, J. C.; Stevenson, S.; Dorn, H. C.; Balch, A. L. J. Am. Chem. Soc. 2000, 122, 12220-12226. (c) Olmstead, M. M.; de Bettencourt-Dias, A.; Duchamp, J. C.; Stevenson, S.; Marciu, D.; Dorn, H. C.; Balch, A. L. Angew. Chem., Int. Ed. 2001, 40, 1223-1225.
(9) (a) Konarev, D. V.; Khasanov, S. S.; Otsuka, A.; Yoshida, Y.; Saito, G. J. Am. Chem. Soc. 2002, 124, 7648-7649. (b) Konarev, D. V.; Khasanov, S. S.; Otsuka, A.; Yoshida, Y.; Lyubovskaya, R. N.; Saito, G. Chem. Eur. J. 2003, 9, 38373848. (c) Konarev, D. V.; Neretin, I. S.; Saito, G.; Slovokhotov, Y. L.; Otsuka, A.; Lyubovskaya, R. N. Dalton Trans. 2003, 3886-3891. (d) Konarev, D. V.; Neretin, I. S.; Saito, G.; Slovokhotov, Y. L.; Otsuka, A.; Lyubovskaya, R. N. Eur. J. Inorg. Chem. 2004, 1794-1798.

(10) Sun, D.; Tham, F. S.; Reed, C. A.; Boyd, P. D. W. Proc. Natl. Acad. Sci. 2002, 99, 5088-5092.

(11) (a) Ellison, M. K.; Scheidt, W. R. J. Am. Chem. Soc. 1999, 121, 5210-5219. (b) Goldberg, I. CrystEngComm 2002, 4 109-116. (c) Kumar, R. K.; Diskin-Posner, Y.; Goldberg I. J. Inclusion Phenom. 2000, 37, 219-230. (d) Kumar, R. K. Goldberg, I. Angew. Chem., Int. Ed. 1998, 37, 3027-3030. (e) Alessio, E.; Geremia, S.; Mestroni, S.; Srnova, I.; Slouf, M.; Gianferrara, T.; Prodi, A. Inorg. Chem. 1999, 38, 25272529. (f) Kumar, R. K.; Balasubramanian, S.; Goldberg, I. Chem. Commun. 1998, 1435-1436. (g) Shukla, A. D.; Dave, P. C.; Suresh, E.; Das, A.; Dastidar, P. J. Chem. Soc., Dalton Trans. 2000, 4459-4463.

(12) Guldi, D. M.; Da Ros, T.; Braiuca, P.; Prato, M.; Alessio, E. J. Mater. Chem. 2002, 12, 2001-2008.

(13) (a) Litvinov, A. L.; Konarev, D. V.; Kovalevsky, A. Y.; Coppens, P.; Lyubovskaya, R. N. CrystEngCommun 2003, 5, 137-139. (b) Konarev, D. V.; Neretin, I. S.; Litvinov, A. L.; Drichko, N. V.; Slovokhotov, Y. L.; Lyubovskaya, R. N.; Howard, J. A. K.; Yufit, D. S. Cryst. Growth Des. 2004, 4, 643-646.

(14) SMART and SAINTPLUS, Area detector control and integration software, Version 6.01; Bruker Analytical X-ray Systems: Madison, WI, 1999.

(15) SHELXTL, An integrated system for solving, refining and displaying crystal structures from diffraction data, Version 5.10; Bruker Analytical X-ray Systems: Madison, WI, 1997.

(16) Zefirov, Y. V.; Zorkii, P. M. Russ. Chem. Rev. 1989, 58, 713746.

(17) Picher, T.; Winkler, R.; Kuzmany, H. Phys. Rev. B 1994, $49,15879-15889$

(18) Semkin, V. N.; Drichko, N. V.; Kimzerov, Y. A.; Konarev, D. V.; Lyubovskaya, R. N.; Graja, A. Chem. Phys. Lett. 1998, $295,266-272$.

(19) (a) Litvinov, A. L.; Konarev, D. V.; Kovalevsky, A. Y.; Lapshin, A. N.; Drichko, N. V.; Yudanova, E. I.; Coppens, P.; Lyubovskaya, R. N. Eur. J. Inorg. Chem. 2003, 39143917. (b) Lee, H. M.; Olmstead, M. M.; Gross, G. G.; Balch, A. L. Cryst. Growth Des. 2003, 3, 691-697.

(20) (a) Konarev, D. V.; Zerza, G.; Scharber, M.; Sariciftci, N. S.; Lyubovskaya, R. N. Synth. Met. 2001, 121, 1127-1128. (b) Konarev, D. V.; Zerza, G.; Scharber, M. C.; Sariciftci, N. S.; Lyubovskaya, R. N. Mol. Cryst. Liq. Crys. 2005, 427, 3/[315]-21/[333]. (c) Lopatin, D. V.; Rodaev, V. V.; Umrikhin, A. V.; Konarev, D. V.; Litvinov, A. L.; Lyubovskaya, R. N. J. Mater. Chem. 2005, 15, 657-660.

\section{CG050095M}

